\title{
A comprehensive analysis of physiologically equivalent temperature changes of Iranian selected stations for the last half century
}

\author{
Gholamreza Roshan $^{1} \cdot$ Robabe Yousefi $^{1} \cdot$ Attila Kovács $^{2} \cdot$ Andreas Matzarakis $^{3}$
}

Received: 4 January 2016 / Accepted: 19 September 2016

(C) Springer-Verlag Wien 2016

\begin{abstract}
As a preliminary and major step for land use planning of the coming years, the study of variability of the past decades' climatic conditions with comprehensive indicators is of high importance. Given the fact that one of the affected areas by climatic change includes variability of thermal comfort, this study uses the physiologically equivalent temperature (PET) to identify and evaluate bioclimatic conditions of 40 meteorological stations in Iran. In this study, PET changes for the period of 1960 to 2010 are analyzed, with the use of Mann-Kendall non-parametric test and Pearson parametric method. The study focuses particularly on the diversity in spatio-temporal distribution of Iran's bioclimatic conditions. The findings show that the mean frequency percentage of days with comfort is $12.9 \%$ according to the total number of selected stations. The maximum and minimum frequency percentage with values of 17.4 and 10.3 belong to Kerman and Chabahar stations, respectively. The findings of long-term trend analysis for the period of 1960-2010 show that $55 \%$ of the stations have significant increasing trend in terms of thermal comfort class based on the Pearson method, while it is $40 \%$ based on Mann-Kendall test. The results indicate that the highest frequency of days with thermal comfort in the southern coasts of Iran relates to the end of autumn and winter, nevertheless, such ideal conditions for the coastal cities of
\end{abstract}

Gholamreza Roshan

r.rowshan@yahoo.com; ghr.roshan@gu.ac.ir

1 Department of Geography, Golestan University, Shahid Beheshti, Gorgan 49138-15759, Iran

2 Department of Climatology and Landscape Ecology, University of Szeged, 2 Egyetem Str, Szeged 6722, Hungary

3 Research Center Human Biometeorology, Deutscher Wetterdienst, Stefan-Meier-Str. 4, D-79104 Freiburg, Germany
Caspian Sea and even central stations of Iran relate to midspring and mid-autumn. Late summer and early autumn along with late spring can be identified as the most ideal times in the west and northwest part of Iran. In addition, the most important inhibiting factors of thermal comfort prove to be different across the regions of Iran. For instance, in the southern coasts, warm to very hot bioclimatic events and in the west and northwest regions, cold to very cold conditions turn out to be the most important inhibiting factors. When considering the variations across the studied period, an increase in the frequency of thermal comfort condition is observed in almost half of the stations. Moreover, based on Pearson and Mann-Kendall methods, the trend of changes in monthly averages of PET has decreased in most stations and months, which can lead to different consequences in each month and station. Thus, it is expected that due to PET changes in recent decades and to the intensified global warming conditions, Iran's bioclimatic conditions change in a way that transfers the days with comfort to early spring and late autumn.

\section{Introduction}

Human biometeorological conditions can be assessed through thermal indices in order to understand the effects of thermal climate on humans (Ndetto and Matzarakis 2015). The thermal comfort state occurs when the human body establishes reasonable balance between the heat generated by the body and its heat loss without unnecessary efforts. Brager et al. (2004) emphasize that the human comfort of individuals is not determined by weather and climate variables only, but two main groups of factors have an impact on it: environmental factors, i.e., air temperature, air humidity, wind speed, and mean radiant temperature, and personal factors, i.e., the type of work activities and clothing's heat resistance. 
The growing need for valid assessment procedures for outdoor thermal environment in the fields of public weather services, public health systems, urban planning, tourism, recreation, and climate impact research led to the development of thermal indices (Jendritzky et al. 2012, Roshan et al. 2015). In fact, one of the main objectives of human bioclimatology is to prepare indicators that combine the physiological effect of complex environmental and personal factors influencing human body (Auliciems and de Dear 1998). Accordingly, since the mid-twentieth century, simple to complex bioclimatic indicators have been developed while their weaknesses and strengths were also demonstrated (Olgyay and Olgyay 1954, Terjung 1968, Fanger 1972, Landsberg 1972, Steadman 1979, Mieczkowski 1985, Gagge et al. 1986, Höppe 1993, Taffé 1997, Höppe 1999, Parsons 2003). These indicators were then applied for various bioclimatic or tourism purposes throughout the world (Matzarakis and Mayer 1997, Zaninovic 2001, McGregor et al. 2002, Yan 2005, Cengiz et al. 2008, Kim et al. 2013, Basarin et al. 2015).

Due to the variability of tourism comfort indices, Abegg et al. (1998) divided all measures into three main groups: simple and preliminary, combined, and bioclimatic indices. The advantage of combined indices and bioclimatic indices is that they consider complex relations between the mechanisms of regulating body temperature and physiological systems of human thermo-circulation. One of the most widely known and applied index of this group is physiologically equivalent temperature (PET). Today, the use of composite indicators that are based on the balance of the human body, e.g. PET, is very common in thermal comfort assessments and tourism climatology. For example, Nastos and Matzarakis (2013) revealed that the trend analysis of PET extremes indicated increasing trends for both extreme heat and cold stress in the Athens University Campus, Greece for the time period of 1999-2007. In another study that considered the role of climate change on thermal comfort conditions in Freiburg, Germany, the results testified to increasing occurrence of heat stress and heat waves and reduced ratio of cold waves for the coming decades (Matzarakis and Endler 2010). Additionally, numerous other researchers used PET in their studies: e.g., Rudel et al. (2007) for Australia, Amiranashvili et al. (2008) for Georgia, Lin et al. (2008) for Taiwan and Krüger et al. (2013) for Glasgow.

Iran has unique features and significant differences in terms of climate conditions, which are due to changes in latitude, altitude, proximity to large watersheds, variety of topographical conditions, and the prevailing circulation systems occurring during the year. These factors induce highly-diverse bioclimatic conditions in terms of temporal and spatial scale in different parts of Iran. The reality of these various conditions are reflected in numerous studies conducted in Iran (Ramezani Gourab and Foroughe, 2010, Delavar et al. 2012, Ramazanipoor and Behzadmoghaddam 2013, Safaeipoor et al. 2013, Esmaili and Fallah Ghalhari 2014b, Roshan et al. 2015, Mokhtari and Anvari 2015). Despite the fact that several studies have focused on the different bioclimate features of Iran so far, their reliance on monthly data and shortterm time series is among their weaknesses. However, Farajzadeh and Matzarakis (2009, 2012) investigated thermal climate and tourism conditions for the areas of northwest of Iran using PET. In addition, based on calculations of PET in Ourmieh Lake coast, it is shown that the months June, July, and August are located in the comfortable class representing the most suitable months for tourist activities. Also, Daneshvar et al. (2013) used long-term average monthly data to estimate PET index and examined thermal comfort conditions during different months of the year. Their results showed that thermal comfort conditions prevail on the southern part of the country and along the shores of the Persian Gulf and Oman Sea during the winter months. In most areas of the country, comfort conditions were observed during the months of spring, especially during April. By examining annual averages of PET, they concluded that the most pleasant comfort conditions can be realized at an altitude of 1000 to $2000 \mathrm{~m}$, with annual air temperatures of 12 to $20{ }^{\circ} \mathrm{C}$ and annual rainfall of $200 \mathrm{~mm}$. Esmaili and Fallah Ghalhari (2014a) studied climatic properties and bioclimatic potential of Iran at a seasonal scale using PET and concluded that the most favorable seasons in terms of thermal comfort are spring and fall, respectively. Dalman et al. (2011) investigated the traditional and modern urban environment in Bandar Abbas in terms of thermal comfort using PET. The results of this study showed the traditional environment has more comfortable situation than the modern one.

Considering the above-mentioned researches and the fact that one of the main concerns refer to the issue of climate change and global warming today, understanding climate behavior in the past is an important step toward detecting the future changes and variations. This issue suggested PET be monitored and evaluated in this study for the first time using daily data for various selected stations of Iran. On the other hand, the change in this index trend based on Pearson and Mann-Kendall test for the last half century (1960-2010) is analyzed. As the changes in the near future are dependent on changes in the past and present decades, their knowledge can be an effective tool to later studies on predicting future conditions in Iran. The aims of this study are to evaluate the bioclimatic conditions and to detect changes of PET for the past decades.

\section{Materials and methods}

In order to achieve this goal, daily, long-term climate data of temperature, relative humidity, wind speed, and cloud cover were used for the period of 1960 to 2010 . In this study, the 
data related to cloud coverage with octa unit has been taken from meteorological stations in Iran, and they are measured and observed by observers in the weather stations.

These data have been obtained from the Iranian Meteorological Organization. Since access to long-term, 50year data is only restricted to a limited number of stations, the statistical assessment has been carried out on the basis of 40 selected stations that have the most complete datasets. It should be noted that data were complete in almost all stations, and less than $2 \%$ of daily data was missing in six stations only, where reconstruction was performed by liner regression and thus the results were approved after validation of reconstructed data. As mentioned above, PET was used in this study to quantify the bioclimatic conditions of the studied areas. PET was developed by Höppe (1999) as a global benchmark for assessing the thermal environment. It has been obtained from the energy balance equation of human body and can be interpreted as the air temperature of a room in which the human body experiences the same level of thermal stress, resulting in the same skin temperature and core temperature of the human body as in the real outdoor environment.

In this study, RayMan model was used to determine PET values and description of this model is available in Matzarakis et al. $(2007,2010)$. One of the important features of this model is simulating the short- and long-wave radiation flux densities from the three-dimensional surroundings in simple and complex environments. The final output of the model is the mean radiant temperature of the environment, which is among the most important components in calculating PET. The variables needed for RayMan to calculate PET included the following:

- Topographical variables, including latitude, longitude, and altitude of the desired area;

- Meteorological variables, including dry air temperature in degrees Celsius, relative humidity in percent or vapor pressure in hectopascal, wind speed in meters per second, and cloudiness in octas;

- Individual variables, such as height, weight, age, gender, type of clothing (in clo), and type of activity (in watt per square meter) are physiological characteristics necessary in the model. Considering the fact that these data are different and variable, they are taken as average or standardized mode in bioclimate models. In this research, the average values of these variables are based on the default model for males, that is height of $1.75 \mathrm{~cm}$, weight of $75 \mathrm{~kg}$, and age of 35 . For the clothing insulation, value of 0.9 clo was taken, and 80 watt was intended for the amount of activity.

In this study, PET has been evaluated from several perspectives. First of all, PET results were compared with those of perceived temperature $(\mathrm{PT})$. $\mathrm{PT}\left({ }^{\circ} \mathrm{C}\right)$ is the air temperature of a reference environment in which the perception of heat and/or cold would be the same as under the actual conditions and that considers a certain degree of adaptation by various clothing (Staiger et al. 1997). The meteorological variable inputs to PT are air temperature, dew point temperature, wind velocity, total cloud cover, and cloud cover of low, medium, and high-level clouds (Jendritzky et al. 2000).

PT is derived from a steady-state model allowing rapid calculation by avoiding integration over time and using an effective iteration. Therefore, it is perfectly suited for operational applications with high spatial and temporal resolution (e.g. meteorological forecasts). The following gives an outline of the human heat budget equations basic to PT and the new parameterisations through which PT is adjusted to physiologically more significant models in the case of both cold and warm humid conditions (Staiger et al. 2012). In Table 1, the threshold values of PET and PT are presented based on varying degrees of thermal stress and human thermal perception (Matzarakis and Mayer 1996, Staiger et al. 2012).

During the comparison of PET and PT, a classification with three new thresholds was proposed and applied (Table 1). The first level consists of comfort zone, and this threshold is consistent with the quantitative values of 18 to $23{ }^{\circ} \mathrm{C}$ and 0 to $20^{\circ} \mathrm{C}$ in the conventional classification of PET and PT.

The second level includes the range higher than comfort, with quantitative threshold values above $23^{\circ} \mathrm{C}$ for PET and $20{ }^{\circ} \mathrm{C}$ for PT. This range can be generally described as the warm zone. Finally, the third level, with values below $18^{\circ} \mathrm{C}$ for PET and $0^{\circ} \mathrm{C}$ for PT, is related to the range lower than the comfort level and can be denominated as the cold zone (Table 1). The purpose of this new classification is summarizing the estimation of frequency of occurrence of each threshold, since considering frequencies for all conventional thermal comfort classes of PET and PT can result in complication and high volume of outputs due to the large volume of input data and studied stations.

There are some studies that calibrated the thermal classes of PET for their specific climate, such as Lin and Matzarakis (2008) for Taiwan, Yahia and Johansson (2013) for Damascus, and Syria or Kovács et al. (2016) for Hungary and Roshan et al. (2017) for Iran. For example, Lin and Matzarakis (2008) defined new PET classes accounting for tourists' thermal perception ranges. They emphasized that in addition to the physiological factor of the human heat balance, thermal sensitivity and thermal comfort ranges vary among residents of different regions due to psychological factors, e.g., people who live in tropical regions might be more tolerant of high temperatures due to their experience. It should be noted that the aim of the present work is not to define and use new thermal zones for Iranian sites. We used the conventional PET classes in this paper generalized for all climatic zones of Iran, therefore its application should be considered only as an indicator at 
this stage of the research. The present study can be the base of a subsequent work where we use calibrated PET classes.

The time scale for the first stage of the examination includes daily data for the whole studied period. The second step of the present study is the calculation of monthly averages of PET from daily data. In this step, firstly, an overview of the long-term monthly averages of each station is presented and then the patterns of each month's trends are calculated along with its decadal changes. Since the analysis of trend of PET changes is a main basis for this study, two parametric methods, Pearson linear regression and Mann-Kendall non-parametric test, were used to detect the trend's changes for the frequencies of the three proposed levels through the monthly time series.

\section{Introduction of representatives of climatic diversity in the study area}

Iran is a country with diverse climate and remarkable topographical variations. Such diversity entailed that besides the overall results for 40 selected stations, certain results are presented exclusively for ten stations as the most representatives of this climatic and geographical diversity. Ahvaz, Boushehr, and Jask, which represent the western, central, and eastern areas of the Persian Gulf, have hot and dry to hot and humid climate (Fig. 1). Reports of 1960-2010 period show that annual average temperature for Ahvaz, Boushehr, and Jask is 25.4, 24.5, and $26.9^{\circ} \mathrm{C}$, while the annual mean relative humidity ranges from $42.6 \%$ for Ahvaz to $65 \%$ for Boushehr and $68 \%$ for Jask. Shiraz and Yazd with cold and dry weather in winter and hot and dry weather in summer were selected as central stations of Iran (Fig. 1). Long-term annual average temperature and relative humidity for Yazd and Shiraz are 19.2 and $30.1 \%$ and 17.9 and $38.9 \%$, respectively. Rasht in the southwest and Babolsar in the east coast of the Caspian Sea are the representative cities of Iran's northern coasts. The relative humidity of Rasht's station reaches $82.2 \%$, while it reduces to $65.1 \%$ in Babolsar. The long-term annual temperature of Babolsar is $17.1{ }^{\circ} \mathrm{C}$, while it is $16.1{ }^{\circ} \mathrm{C}$ in Rasht. Mashhad station representing northeast of Iran shows average temperature and relative humidity of 14.3 and $54.7 \%$, respectively. Tehran, which was selected for both its climatic pattern and commercial position, has average annual temperature and relative humidity of 17.5 and $40.3 \%$, respectively. Tabriz, the representative of the northwest stations of Iran, has an annual average temperature and relative humidity of 12.7 and $52.5 \%$, respectively (Fig. 1).

In order to provide an overview of the diversity of climate and topography of Iran, Fig. 1 is presented. The present climatic zoning map is derived from the results of a work provided by Hydarei and Alijanei (1999). For climatic zoning of Iran using minimum, maximum, and average monthly temperature; dew point; frosty days; direction and speed of wind; the amount of rain and number of rainy days; snowy days; relative humidity; air pressure and sunshine hours on monthly basis; and cluster analysis, they have determined six mesoclimatic zones for Iran.

\section{Results}

\subsection{Monitoring of the frequency pattern of proposed thermal comfort classes}

In Fig. 2, the percentages of frequencies of occurrence of each three proposed thermal comfort class of PET and PT that include comfort, heat, and cool zonesare illustrated for each selected station based on daily data. The minimum and maximum frequencies of the comfort class for the PET belong to

Table 1 Traditional thresholds of PET (Matzarakis and Mayer 1996) and PT (Staiger et al. 2012) as well as the proposed category boundaries used in the present study

\begin{tabular}{|c|c|c|c|c|c|}
\hline \multicolumn{2}{|c|}{ Suggested categorization in this paper } & \multirow{2}{*}{$\begin{array}{l}\text { Level of thermal stress (PET) } \\
\text { Extreme cold stress }\end{array}$} & \multirow{2}{*}{$\begin{array}{l}\text { Thermal perception } \\
\text { for PET and PT } \\
\text { Very cold }\end{array}$} & \multirow{2}{*}{$\begin{array}{l}\mathrm{PT}\left({ }^{\circ} \mathrm{C}\right) \\
-39>\end{array}$} & \multirow{2}{*}{$\frac{\operatorname{PET}\left({ }^{\circ} \mathrm{C}\right)}{<4}$} \\
\hline $\mathrm{PT}\left({ }^{\circ} \mathrm{C}\right)$ & $\operatorname{PET}\left({ }^{\circ} \mathrm{C}\right)$ & & & & \\
\hline \multirow[t]{4}{*}{ Cold $<0$} & Cold $<18$ & & & & \\
\hline & & Strong cold stress & Cold & -39 to -26 & $4-8$ \\
\hline & & Moderate cold stress & Cool & -26 to -13 & $8-13$ \\
\hline & & Slight cold stress & Slightly cool & -13 to 0 & $13-18$ \\
\hline Comfortable & Comfortable & No thermal stress & Comfortable & 0 to 20 & $18-23$ \\
\hline $0-20$ & $18-23$ & & & & \\
\hline \multirow[t]{4}{*}{ Warm $>20$} & Warm $>23$ & Slight heat stress & Slightly warm & 20 to 26 & $23-29$ \\
\hline & & Moderate heat stress & Warm & 26 to 32 & $29-35$ \\
\hline & & Strong heat stress & Hot & 32 to 38 & $35-41$ \\
\hline & & Extreme heat stress & Very hot & $>38$ & $>41$ \\
\hline
\end{tabular}




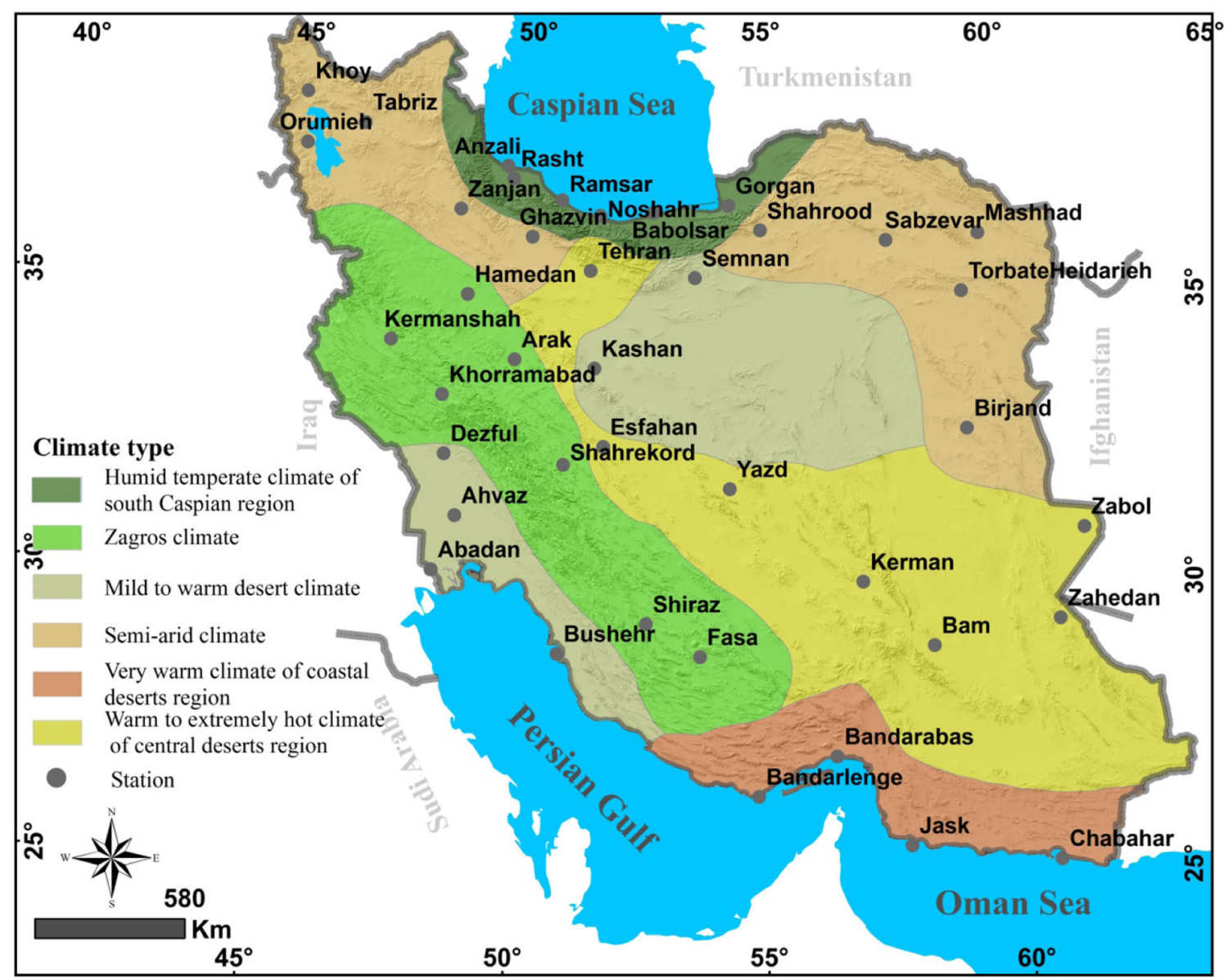

Fig. 1 Map of Iran's climatic diversity, as well as the distribution of studied stations

Chabahar and Kerman stations with values of 10.3 and $17.4 \%$, respectively, while the average percentage of days with comfort considering all selected stations is $12.9 \%$. Comparing the frequencies of three above-mentioned thermal comfort classes indicates the highest percentage of frequencies of PET in the warm zone: the average frequency for all studied stations is $51.4 \%$ in the case of the warm class, while this value is $35.7 \%$ for the cold class. In the warm class, the minimum frequency belongs to Hamedan station with $24.9 \%$ and Tabriz with $28.5 \%$. However, Chabahar and Dezfool experienced the highest ratio of warm conditions with frequency percentages of 86.7 and $85.2 \%$. Considering the cold class, the results tend to be contrary to those of the warm zone (Fig. 2). Chabahar and Dezfool experienced the least cold conditions with 3 and $3.7 \%$ frequencies, while Hamedan and Tabriz have the highest frequency of cold class with 62.1 and $58.6 \%$. Overall, Fig. 2 clearly shows that the highest frequency of bioclimatic conditions related to PET is related to the warm class on average, which is followed by the frequency percentage of cold and thermal comfort zone.

The most striking results in Fig. 2. concern the comparison of PET and PT frequencies. The smallest differences between the two can be observed in the case of the warm class, where almost full overlaps appear in most cases. However, the diversity is the highest concerning the cold class. The warm-related frequencies indicate higher PET values compared to PT in almost all stations, but these differences are negligible. However, the cold conditions occur much more frequently in each station when considering the PET. Paying our attention to overall averages of the studied areas concerning cold bioclimatic classification, $36 \%$ of the days are in the cold range based on PET, while this average amount covers $5 \%$ for PT only (Fig. 2). These facts reflect that the quantitative thresholds of PET have more sensitivity during the occurrence of cold bioclimatic conditions compared to PT. The higher sensitivity of PET to the occurrence of cold conditions caused that the ratio of comfortable days are much fewer in terms of PET compared to PT. The overall average of this frequency in the studied stations is $13 \%$ for PET, while this is $59 \%$ in the case of PT (Fig. 2).

An interesting point during the assessment is the study of trends of frequency changes for each three proposed class concerning PET (Tables 2 and 3, Fig. 3). Based on Pearson's correlation coefficients, it is specified that the 

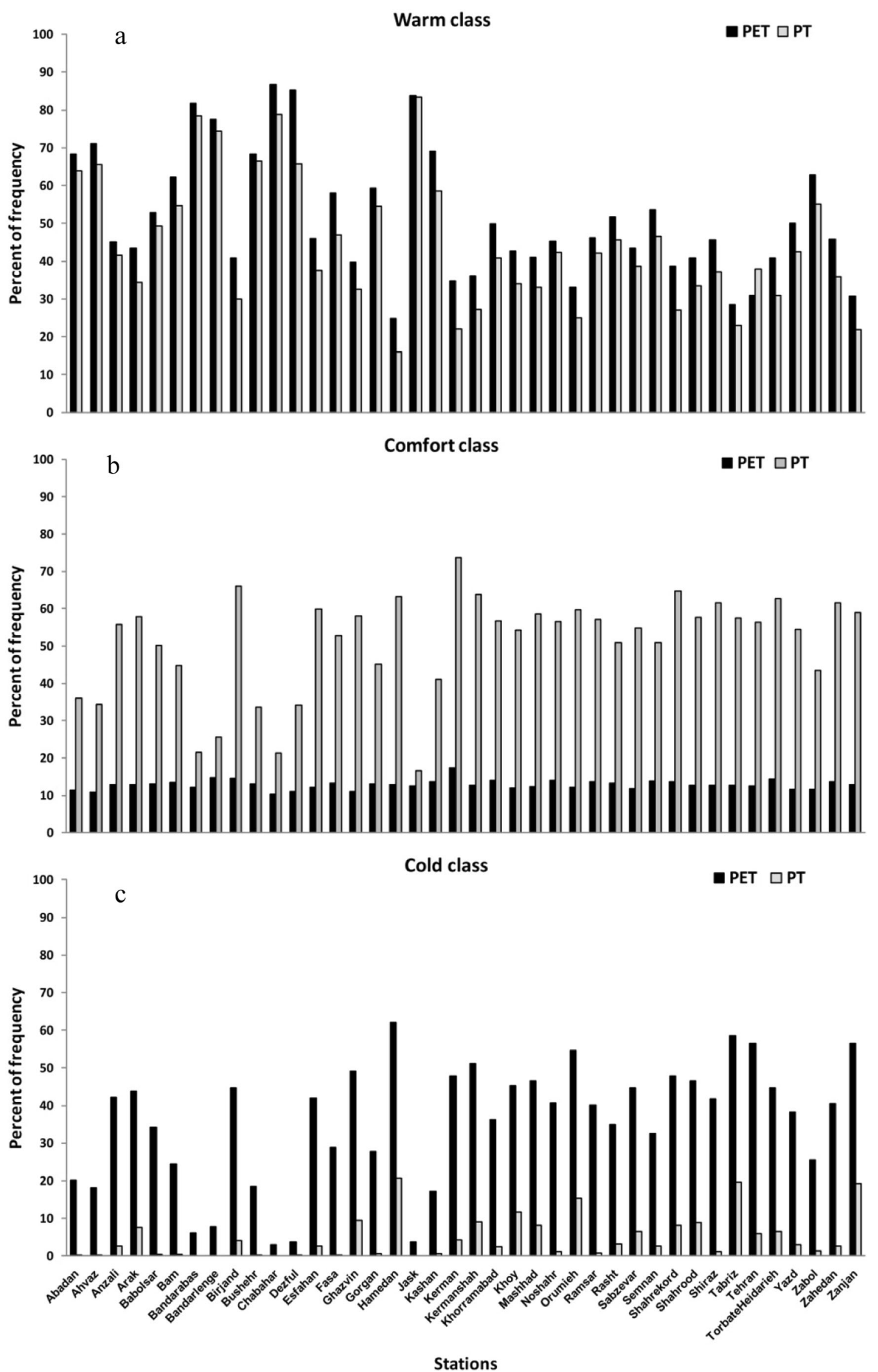
Fig. 2 Percentage of frequency (\%) of warm (a), comfort (b), and cold (c) thermal classes of selected Iranian stations for PET and PT index based on daily data of 1960 to 2010. The applied PET and PT warm, comfortable, and cold category boundaries are based on the suggested categorization system of Table 1

trend of changes in thermal comfort is significant increasing in $55 \%$ while significant decreasing in $7.5 \%$ of the studied stations (Table 2, Fig. 3). The frequency trend of warm conditions decreases significantly in $55 \%$ of the areas, while significant increase occurs with $10 \%$. In terms of cold conditions, significant increase prevails in $40 \%$ and decrease in $2.5 \%$ of the places only.

Somewhat different results are observed using MannKendall method (Table 3, Fig. 3). Forty percent of the stations show significant increasing trend for climate comfort class, while significant decreasing trend does not occur at all. On the other hand, the results show that the frequency percentage of stations with decreasing and increasing significant trend for cold class include 10 and $47.5 \%$ of the studied stations, respectively, which are slightly higher than those according to the Pearson's method (Fig. 3). Finally, for warm class, $5 \%$ of the stations have significant increasing and $40 \%$ of them have significant decreasing trend, which signals slightly lower cases compared to the Pearson's method (Table 3, Fig. 3).

\section{Evaluation of monthly averages and changes of PET}

One of the aims of this study is to present a general overview of Iran's bioclimatic conditions. In order to achieve this goal, long-term monthly averages of PET were calculated for all stations using the daily data, and then, the frequencies for the different thermal comfort classes for each month are also analyzed (Table 4, Fig. 4). As winter starts in December in Iran, the data signal no evidence of warm to very hot events for this month in the studied stations, while in January, it does not reach even the slightly warm class, i.e., the value of $23^{\circ} \mathrm{C}$ (Table 4, Fig. 4). In February, the situation is similar to December with no occurrence of frequencies for warm to very hot classes. The frequency of cool class dominates in all winter months and distributes in similar proportion, i.e., $32.5 \%$ for December, $30 \%$ for January, and $32.5 \%$ for February, respectively (Fig. 4). Generally, the lowest monthly PET averages belong to Tabriz, Tehran, Zanjan, Hamedan, and Urumieh, while the stations of Chabahar, Dezfool, Jask, and Bandar Abbas experienced the highest PET in winter (Table 4).

In March, classes range from cold to warm, in April from cool to hot, while in May from slightly cool to very hot. In March, the most frequent bioclimatic condition across the stations corresponds to the slightly cool class with $30 \%$. The highest occurrence rate belongs to the comfort class in April
Table 2 Pearson's correlation coefficients $(r)$ for assessing meaningfulness and randomness of the trend of frequency changes of the proposed thermal zones concerning PET (the minimum significance in $5 \%$ level equals to $r= \pm 0.23$, and significant trends are highlighted). The applied PET warm, comfort, and cold category boundaries are based on the suggested categorization system of Table 1

\begin{tabular}{llllllll}
\hline Station & Warm & Comfort & Cold & Station & Warm & Comfort & Cold \\
\hline Abadan & 0.04 & -0.02 & -0.05 & Kermanshah & 0.00 & 0.00 & 0.01 \\
Ahvaz & -0.09 & 0.01 & 0.02 & Khorramabad & -0.63 & 0.55 & 0.10 \\
Anzali & -0.42 & 0.40 & 0.13 & Khoy & -0.20 & 0.24 & -0.02 \\
Arak & -0.69 & 0.61 & 0.41 & Mashhad & -0.27 & 0.16 & 0.28 \\
Babolsar & -0.37 & 0.39 & -0.13 & Noshahr & -0.61 & 0.89 & 0.40 \\
Bam & -0.02 & 0.03 & -0.04 & Orumieh & -0.52 & 0.53 & 0.11 \\
Bandarabas & -0.37 & 0.42 & 0.19 & Ramsar & -0.30 & 0.28 & 0.01 \\
Bandarlenge & 0.02 & 0.17 & -0.07 & Rasht & -0.32 & 0.38 & -0.12 \\
Birjand & -0.31 & 0.22 & 0.32 & Sabzevar & -0.03 & -0.08 & 0.43 \\
Bushehr & 0.08 & 0.04 & -0.34 & Semnan & -0.30 & 0.37 & -0.03 \\
Chabahar & -0.40 & 0.60 & 0.67 & Shahrekord & -0.76 & 0.74 & 0.45 \\
Dezful & -0.27 & 0.60 & 0.48 & Shahrood & 0.35 & -0.50 & 0.45 \\
Esfahan & 0.24 & -0.34 & 0.38 & Shiraz & 0.28 & -0.31 & 0.16 \\
Fasa & 0.25 & 0.24 & 0.12 & Tabriz & -0.12 & 0.17 & -0.09 \\
Ghazvin & 0.01 & -0.07 & 0.16 & Tehran & 0.22 & -0.18 & -0.18 \\
Gorgan & -0.61 & 0.60 & 0.06 & TorbateHeidarieh & -0.51 & 0.34 & 0.52 \\
Hamedan & -0.41 & 0.31 & 0.41 & Yazd & -0.02 & 0.02 & 0.02 \\
Jask & -0.54 & 0.54 & 0.61 & Zabol & -0.75 & 0.86 & 0.23 \\
Kashan & -0.35 & 0.57 & 0.23 & Zahedan & -0.14 & 0.16 & 0.01 \\
Kerman & 0.12 & -0.15 & 0.07 & Zanjan & -0.77 & 0.76 & 0.59 \\
\hline & & & & & & &
\end{tabular}


Table 3 Mann-Kendall coefficients to detect significant trends of frequency changes of the proposed thermal zones concerning PET (the minimum significance in $5 \%$ level equals to $t= \pm 0.19$, and significant trends are highlighted). The applied PET warm, comfort, and cold category boundaries are based on the suggested categorization system of Table 1

Fig. 3 Frequency percentage of Iranian stations with significant decreasing (a) and increasing (b) trend concerning warm, comfortable, and cold thermal classes of PET based on MannKendall and Pearson's tests. The applied PET warm, comfortable, and cold category boundaries are based on the suggested categorization system of Table 1

\begin{tabular}{llllllll}
\hline Station & Warm & Comfort & Cold & Station & Warm & Comfort & Cold \\
\hline Abadan & 0.03 & 0.04 & -0.02 & Kermanshah & 0.01 & 0.08 & 0.03 \\
Ahvaz & -0.05 & 0.02 & 0.04 & Khorramabad & -0.31 & 0.09 & 0.28 \\
Anzali & -0.21 & 0.18 & 0.27 & Khoy & -0.12 & 0.04 & 0.15 \\
Arak & -0.43 & 0.34 & 0.41 & Mashhad & -0.11 & 0.22 & 0.1 \\
Babolsar & -0.11 & 0 & 0.19 & Noshahr & -0.22 & 0.4 & 0.71 \\
Bam & 0.02 & 0.05 & 0.04 & Orumieh & -0.29 & 0.1 & 0.35 \\
Bandarabas & -0.21 & 0.16 & 0.27 & Ramsar & -0.09 & 0.06 & 0.14 \\
Bandarlenge & 0.1 & -0.06 & -0.24 & Rasht & -0.15 & -0.03 & 0.22 \\
Birjand & -0.12 & 0.26 & 0.13 & Sabzevar & 0.04 & 0.31 & -0.04 \\
Bushehr & 0.07 & -0.17 & 0.05 & Semnan & -0.03 & 0.06 & 0.12 \\
Chabahar & -0.26 & 0.35 & 0.43 & Shahrekord & -0.5 & 0.35 & 0.52 \\
Dezful & -0.23 & 0.35 & 0.47 & Shahrood & 0.24 & 0.29 & -0.35 \\
Esfahan & 0.22 & 0.27 & -0.25 & Shiraz & 0.24 & 0.13 & -0.18 \\
Fasa & 0.13 & 0.11 & 0.22 & Tabriz & -0.03 & -0.01 & 0.11 \\
Ghazvin & 0.02 & 0.16 & 0.01 & Tehran & 0.18 & -0.09 & -0.12 \\
Gorgan & -0.29 & 0.09 & 0.31 & TorbateHeidarieh & -0.27 & 0.39 & 0.21 \\
Hamedan & -0.27 & 0.31 & 0.2 & Yazd & 0 & 0.07 & 0.02 \\
Jask & -0.29 & 0.42 & 0.27 & Zabol & -0.59 & 0.2 & 0.65 \\
Kashan & -0.19 & 0.2 & 0.38 & Zahedan & -0.09 & 0.08 & 0.15 \\
Kerman & 0.07 & 0.04 & -0.6 & Zanjan & -0.5 & 0.46 & 0.53 \\
\hline & & & & & & & \\
\hline
\end{tabular}

a

Negative trend

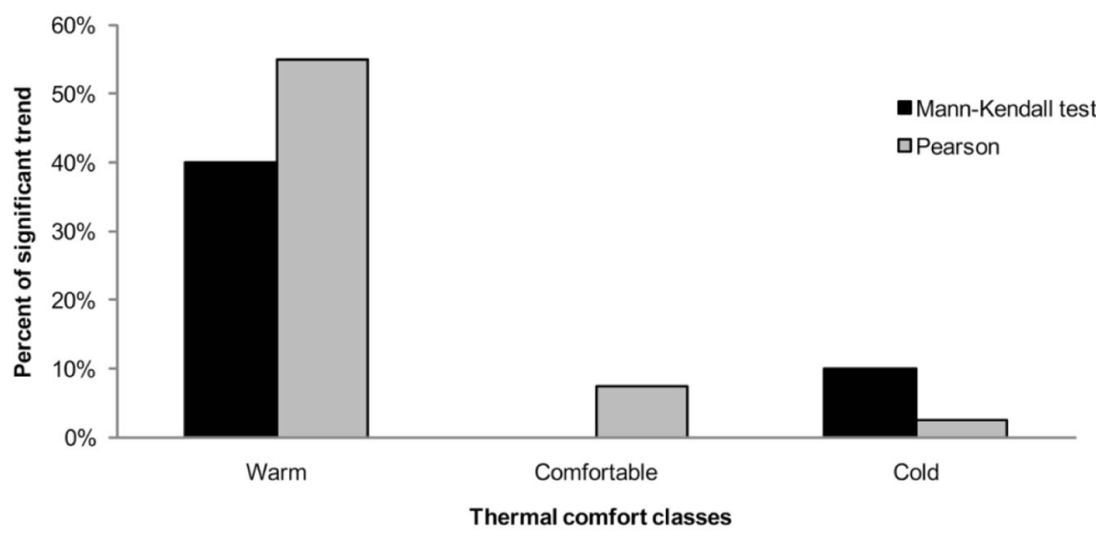

b

Positive trend

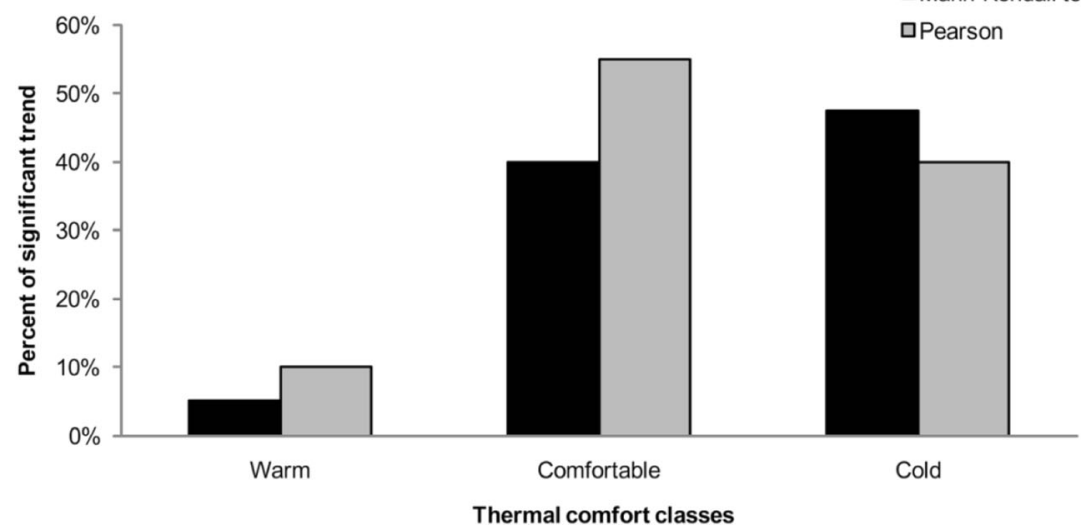


Table 4 Long-term monthly averages of PET for selected Iranian stations

\begin{tabular}{|c|c|c|c|c|c|c|c|c|c|c|c|c|}
\hline STATION & Jan & Feb & Mar & Apr & May & Jun & Jul & Aug & Sep & Oct & Nov & Dec \\
\hline Abadan & 14.7 & 17.4 & 22.8 & 30.2 & 38.8 & 44.3 & 46.9 & 46.7 & 42.6 & 35.0 & 23.5 & 16.4 \\
\hline Ahvaz & 18.9 & 25.9 & 33.6 & 40.4 & 45.4 & 47.9 & 46.5 & 42.6 & 33.6 & 24.9 & 18.4 & 16.4 \\
\hline Anzali & 7.8 & 9.2 & 13.0 & 19.4 & 26.3 & 32.3 & 35.7 & 34.7 & 29.2 & 22.3 & 15.6 & 10.3 \\
\hline Arak & 6.1 & 7.9 & 12.2 & 17.9 & 24.6 & 32.7 & 36.9 & 35.6 & 30.3 & 21.7 & 14.8 & 8.1 \\
\hline Babolsar & 11.3 & 11.9 & 15.0 & 21.2 & 27.9 & 34.1 & 37.1 & 36.7 & 32.6 & 26.0 & 19.1 & 13.6 \\
\hline Bam & 12.6 & 16.0 & 21.7 & 28.2 & 35.3 & 41.1 & 42.0 & 39.5 & 35.0 & 27.8 & 19.7 & 14.5 \\
\hline Bandarabas & 20.3 & 22.5 & 27.1 & 32.8 & 39.4 & 43.6 & 44.1 & 43.2 & 41.1 & 36.6 & 28.5 & 22.3 \\
\hline Bandarlenge & 19.5 & 21.3 & 24.9 & 31.2 & 37.6 & 41.4 & 43.2 & 43.1 & 40.1 & 34.7 & 27.3 & 21.8 \\
\hline Birjand & 5.7 & 8.1 & 13.5 & 20.1 & 26.0 & 31.4 & 32.4 & 30.3 & 26.4 & 19.9 & 12.7 & 7.4 \\
\hline Bushehr & 15.7 & 17.6 & 22.0 & 29.1 & 36.0 & 40.3 & 43.2 & 43.7 & 40.8 & 34.0 & 24.3 & 17.8 \\
\hline Chabahar & 23.0 & 24.9 & 29.5 & 34.7 & 40.1 & 41.6 & 39.4 & 37.5 & 37.3 & 36.0 & 30.7 & 25.2 \\
\hline Dezful & 22.1 & 24.3 & 29.1 & 34.4 & 40.2 & 42.4 & 40.7 & 38.9 & 38.1 & 35.7 & 30.0 & 24.3 \\
\hline Esfahan & 8.6 & 9.6 & 13.4 & 19.1 & 25.5 & 33.3 & 36.6 & 35.1 & 30.9 & 22.9 & 15.8 & 10.3 \\
\hline Fasa & 12.9 & 14.6 & 18.6 & 24.2 & 30.9 & 38.1 & 40.3 & 39.2 & 34.3 & 26.6 & 18.9 & 14.6 \\
\hline Ghazvin & 3.6 & 5.4 & 10.2 & 17.1 & 23.7 & 30.3 & 34.6 & 33.9 & 28.5 & 19.9 & 11.7 & 5.9 \\
\hline Gorgan & 12.8 & 14.6 & 18.2 & 24.9 & 30.8 & 36.0 & 39.1 & 39.1 & 35.3 & 28.2 & 20.7 & 14.7 \\
\hline Hamedan & -1.0 & 1.5 & 6.0 & 11.7 & 17.1 & 23.2 & 27.1 & 26.3 & 21.5 & 15.0 & 8.1 & 2.0 \\
\hline Jask & 21.4 & 22.8 & 26.9 & 32.8 & 38.3 & 40.8 & 39.6 & 38.2 & 37.2 & 35.0 & 28.9 & 23.7 \\
\hline Kashan & 15.6 & 18.2 & 23.8 & 29.9 & 36.7 & 45.8 & 48.3 & 46.8 & 42.5 & 32.9 & 23.4 & 17.0 \\
\hline Kerman & 6.6 & 8.0 & 11.9 & 17.3 & 23.2 & 29.4 & 30.7 & 28.0 & 24.1 & 18.5 & 12.8 & 8.6 \\
\hline Kermanshah & 2.6 & 4.7 & 9.4 & 15.0 & 21.2 & 28.5 & 34.4 & 33.5 & 27.0 & 19.2 & 12.0 & 5.7 \\
\hline Khorramabad & 9.4 & 11.5 & 15.7 & 20.8 & 27.4 & 35.7 & 40.3 & 39.3 & 32.6 & 24.3 & 16.5 & 10.9 \\
\hline Khoy & 3.2 & 6.8 & 13.1 & 19.1 & 25.2 & 32.0 & 37.6 & 37.1 & 30.7 & 21.6 & 13.1 & 6.1 \\
\hline Mashhad & 4.1 & 6.6 & 11.6 & 18.8 & 23 & 31.0 & 33.5 & 31.6 & 26.1 & 18.9 & 12.5 & 6.7 \\
\hline Noshahr & 9.2 & 9.9 & 13.1 & 19.1 & 25.2 & 31.5 & 35.0 & 35.0 & 30.6 & 23.5 & 16.5 & 11.7 \\
\hline Orumieh & 0.5 & 3.4 & 9.3 & 14.4 & 20.8 & 27.4 & 32.5 & 31.8 & 25.5 & 17.5 & 9.7 & 3.2 \\
\hline Ramsar & 9.5 & 10.3 & 13.3 & 19.0 & 25.4 & 31.6 & 34.8 & 34.8 & 30.2 & 23.7 & 17.1 & 11.8 \\
\hline Rasht & 9.4 & 11.1 & 15.6 & 22.0 & 28.9 & 34.9 & 37.7 & 36.6 & 31.6 & 25.0 & 17.8 & 12.1 \\
\hline Sabzevar & 3.6 & 6.7 & 12.6 & 20.2 & 27.0 & 34.0 & 36.6 & 34.4 & 28.8 & 20.2 & 12.1 & 6.1 \\
\hline Semnan & 9.8 & 12.4 & 17.3 & 23.9 & 30.7 & 39.0 & 42.5 & 41.5 & 35.1 & 25.6 & 17.0 & 11.3 \\
\hline Shahrekord & 6.5 & 8.7 & 10.8 & 16.6 & 22.8 & 31.2 & 34.4 & 33.6 & 28.6 & 20.5 & 13.9 & 8.2 \\
\hline Shahrood & 3.5 & 6.0 & 11.4 & 18.6 & 24.9 & 30.5 & 33.2 & 32.6 & 28.6 & 20.7 & 11.7 & 5.6 \\
\hline Shiraz & 8.3 & 10.2 & 13.9 & 19.3 & 25.9 & 33.4 & 36.9 & 35.9 & 30.7 & 22.9 & 15.4 & 10.3 \\
\hline Tabriz & -3.1 & 0.0 & 6.2 & 12.7 & 19.0 & 25.6 & 30.2 & 29.8 & 24.8 & 16.2 & 7.7 & 0.2 \\
\hline Tehran & -1.9 & 1.0 & 7.1 & 13.5 & 19.9 & 26.7 & 31.2 & 30.6 & 25.7 & 17.1 & 8.8 & 1.4 \\
\hline TorbateHeidarieh & 5.7 & 8.0 & 12.6 & 19.3 & 25.0 & 30.8 & 32.1 & 30.7 & 27.3 & 20.1 & 13.2 & 7.9 \\
\hline Yazd & 6.7 & 10.3 & 15.6 & 22.2 & 29.5 & 37.3 & 39.6 & 37.3 & 32.2 & 23 & 14.8 & 8.4 \\
\hline Zabol & 12.6 & 15.6 & 21.4 & 29.1 & 34.1 & 39.1 & 40.8 & 37.7 & 31.5 & 25.5 & 19.8 & 14.7 \\
\hline Zahedan & 6.8 & 9.9 & 15.3 & 22.3 & 28.4 & 32.8 & 34.1 & 32.0 & 27.1 & 21.3 & 14.5 & 8.8 \\
\hline Zanjan & -1.8 & 1.3 & 7.1 & 13.8 & 20.3 & 26.9 & 31.1 & 30.6 & 25.8 & 17.6 & 8.8 & 1.5 \\
\hline
\end{tabular}

(40\%) and to the slightly warm class in May (45\%) (Fig. 4). In May, Hamedan, Tabriz, Zanjan, and Tehran experienced the lowest averages of PET, while Ahvaz, Dezfool, and Chabahar have the maximum ones (Table 4).

From the beginning of summer, none of the months from June to August experienced comfortable or any cold bioclimatic classes (Table 4, Fig. 4). The highest frequencies reallocated to the warm class with $45 \%$ in June and $40 \%$ in August and to the hot class with $40 \%$ in July (Fig. 4). In this season, stations of Hamedan, Tabriz, and Kerman experienced the minimum and Kashan, Abadan, and Ahvaz the maximum averages of PET (Table 4).

In September, warm condition occurs the most frequently with $37.5 \%$. In October, in line with the start 
Fig. 4 Frequencies of slightly cool to very cold (a), comfortable (b), and slightly warm to very hot (c) thermal classes of selected Iranian stations in each month concerning PET. The applied PET class boundaries are based on the traditional thermal perception thresholds of PET in Table 1 (Matzarakis and Mayer 1996) $\mathrm{a}$
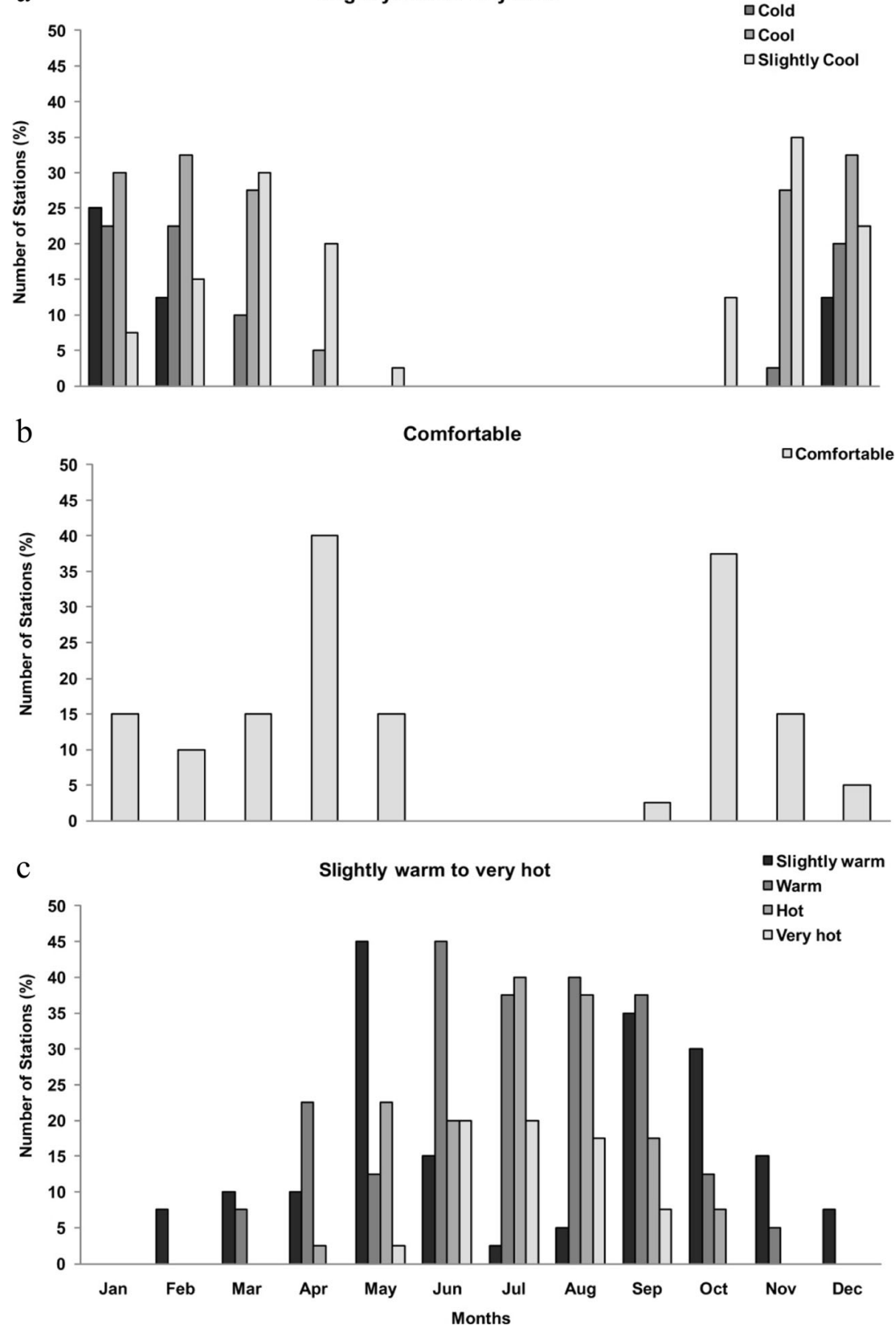

of the cold period of the year, the frequency of stations located in very hot class reaches zero and the slightly cool class appears. Interestingly, the maximum frequency of the comfortable class is allocated to this month after April (37.5\%) (Fig. 4). In November, the most frequent class is the slightly cool with $35 \%$ of rate of occurrence, while slightly warm and warm conditions significantly decreased and classes from hot to very hot do not occur at all (Fig. 4). It should be noted that in autumn, Hamedan, Tabriz, Tehran, Kerman, and Urumieh experienced the minimum PET averages, while the highest averages of PET belong to the cities of Chabahar, Dezfool, Bandar Abbas, and Abadan (Table 4).
We can conclude in this section that the most appropriate season in terms of prevailing bioclimatological conditions is spring, following with autumn and winter. Due to the lack of comfort conditions and the high frequencies of warm to very hot classes, summer seems to be the most unfavorable season. On the other hand, when comparing summer and winter, we can observe far more unfavorable inhibiting factors of thermal comfort in summer than in winter.

In the following cases, the long-term monthly changes of PET and the changes in decadal averages of PET are analyzed for the 40 selected stations. As shown in Table 5 and Fig. 5, the significant trend of monthly changes of PET based on both Mann-Kendall and Pearson tests is mostly decreasing. For 
Table 5 Pearson's correlation coefficients for assessing meaningfulness and randomness of monthly trends of PET (the minimum significance in $5 \%$ level equals to $r= \pm 0.23$, and significant trends are highlighted)

\begin{tabular}{|c|c|c|c|c|c|c|c|c|c|c|c|c|}
\hline Station & Jan & Feb & Mar & Apr & May & Jun & Jul & Aug & Sep & Oct & Nov & Dec \\
\hline Abadan & 0.03 & -0.05 & 0.09 & 0.2 & 0.26 & 0.3 & 0.16 & 0.3 & -0.02 & 0.11 & -0.1 & 0.06 \\
\hline Ahvaz & 0.02 & 0.13 & 0.17 & 0.22 & 0.22 & 0.22 & -0.11 & -0.1 & -0.22 & -0.14 & -0.19 & -0.11 \\
\hline Anzali & -0.17 & -0.31 & -0.39 & -0.4 & -0.5 & -0.41 & -0.38 & -0.34 & -0.3 & -0.16 & -0.37 & -0.25 \\
\hline Arak & -0.36 & -0.45 & -0.5 & -0.6 & -0.66 & -0.71 & -0.71 & -0.51 & -0.57 & -0.52 & -0.51 & -0.24 \\
\hline Babolsar & -0.31 & -0.39 & -0.36 & -0.4 & -0.5 & -0.38 & -0.4 & -0.41 & -0.38 & -0.28 & -0.28 & -0.31 \\
\hline Bam & -0.08 & -0.04 & -0.12 & 0.01 & 0.07 & -0.01 & 0.12 & 0.04 & -0.03 & -0.17 & -0.1 & -0.02 \\
\hline Bandarabas & -0.29 & -0.35 & -0.33 & -0.08 & 0.07 & -0.11 & -0.15 & -0.23 & -0.3 & -0.24 & -0.27 & -0.25 \\
\hline Bandarlenge & -0.09 & 0.05 & 0.16 & -0.02 & 0.06 & -0.04 & 0.08 & 0.08 & 0.13 & 0.22 & 0.08 & -0.02 \\
\hline Birjand & -0.26 & -0.28 & -0.33 & -0.21 & -0.33 & -0.4 & -0.33 & -0.3 & -0.17 & -0.19 & -0.21 & -0.14 \\
\hline Bushehr & -0.08 & -0.03 & 0.01 & 0.13 & 0.14 & 0.09 & 0.04 & 0.14 & 0.13 & 0.25 & 0.06 & 0.09 \\
\hline Chabahar & -0.52 & -0.49 & -0.44 & -0.33 & -0.24 & -0.26 & -0.29 & -0.29 & -0.33 & -0.41 & -0.43 & -0.5 \\
\hline Dezful & -0.42 & -0.4 & -0.37 & -0.29 & -0.18 & 0.02 & 0.11 & 0.12 & 0.05 & -0.21 & -0.26 & -0.36 \\
\hline Esfahan & 0.55 & 0.42 & 0.42 & 0.32 & -0.07 & -0.22 & -0.24 & -0.16 & -0.08 & 0.19 & 0.5 & 0.63 \\
\hline Fasa & 0.27 & 0.16 & 0.03 & 0.15 & -0.05 & -0.05 & 0.05 & 0 & 0.02 & 0.14 & 0.25 & 0.31 \\
\hline Ghazvin & 0.16 & 0.01 & 0.03 & 0.08 & -0.01 & -0.01 & -0.1 & -0.04 & 0 & 0.02 & -0.11 & -0.03 \\
\hline Gorgan & -0.58 & -0.6 & -0.53 & -0.46 & -0.5 & -0.41 & -0.32 & -0.28 & -0.36 & -0.49 & -0.65 & -0.64 \\
\hline Hamedan & 0.14 & 0.04 & -0.02 & -0.02 & -0.35 & -0.4 & -0.45 & -0.43 & -0.44 & -0.48 & -0.24 & 0.12 \\
\hline Jask & -0.58 & -0.44 & -0.61 & -0.51 & -0.49 & -0.52 & -0.7 & -0.77 & -0.61 & -0.56 & -0.56 & -0.58 \\
\hline Kashan & -0.34 & -0.36 & -0.36 & -0.38 & -0.59 & -0.43 & -0.56 & -0.27 & -0.56 & -0.5 & -0.6 & -0.47 \\
\hline Kerman & 0.02 & 0.04 & -0.03 & 0.14 & 0.08 & 0.01 & 0.17 & 0.2 & 0.17 & 0.14 & 0.13 & 0.21 \\
\hline Kermanshah & -0.06 & -0.04 & 0.06 & 0.07 & -0.05 & 0.02 & -0.09 & 0.02 & -0.01 & 0.08 & -0.13 & 0.05 \\
\hline Khorramabad & -0.5 & -0.55 & -0.54 & -0.45 & -0.62 & -0.76 & -0.77 & -0.74 & -0.65 & -0.64 & -0.59 & -0.47 \\
\hline Khoy & 0 & -0.16 & -0.27 & -0.17 & -0.2 & -0.21 & -0.24 & -0.1 & -0.05 & 0.01 & -0.08 & -0.13 \\
\hline Mashhad & -0.15 & -0.16 & -0.15 & -0.13 & -0.24 & -0.2 & -0.2 & -0.09 & -0.14 & -0.11 & -0.24 & -0.18 \\
\hline Noshahr & -0.41 & -0.45 & -0.39 & -0.41 & -0.48 & -0.36 & -0.41 & -0.4 & -0.38 & -0.33 & -0.38 & -0.36 \\
\hline Orumieh & -0.23 & -0.31 & -0.49 & -0.36 & -0.51 & -0.48 & -0.5 & -0.51 & -0.48 & -0.47 & -0.55 & -0.38 \\
\hline Ramsar & -0.2 & -0.21 & -0.2 & -0.23 & -0.32 & -0.21 & -0.25 & -0.25 & -0.3 & -0.17 & -0.35 & -0.39 \\
\hline Rasht & -0.14 & -0.26 & -0.3 & -0.25 & -0.38 & -0.25 & -0.25 & 0 & -0.06 & -0.05 & -0.27 & -0.35 \\
\hline Sabzevar & 0.1 & 0.04 & 0.05 & 0.03 & -0.09 & -0.04 & -0.02 & 0.06 & -0.02 & 0.1 & 0.05 & 0.11 \\
\hline Semnan & -0.47 & -0.35 & -0.26 & -0.15 & -0.27 & -0.26 & -0.3 & -0.32 & -0.21 & -0.19 & -0.42 & -0.5 \\
\hline Shahrekord & -0.6 & -0.75 & -0.68 & -0.66 & -0.65 & -0.79 & -0.69 & -0.69 & -0.7 & -0.66 & -0.72 & -0.54 \\
\hline Shahrood & 0.5 & 0.45 & 0.47 & 0.38 & 0.27 & 0.17 & 0.03 & 0.2 & 0.34 & 0.55 & 0.44 & 0.47 \\
\hline Shiraz & 0.13 & 0.17 & 0.1 & 0.25 & 0.23 & 0.13 & 0.22 & 0.3 & 0.19 & 0.29 & 0.28 & 0.29 \\
\hline Tabriz & 0.03 & -0.03 & -0.12 & -0.1 & -0.23 & -0.1 & -0.15 & 0.02 & -0.06 & -0.06 & -0.28 & -0.12 \\
\hline Tehran & 0.29 & 0.19 & 0.2 & 0.14 & 0.07 & 0.21 & 0.19 & 0.35 & 0.18 & 0.23 & -0.02 & 0.14 \\
\hline TorbateHeidarieh & -0.12 & -0.26 & -0.27 & -0.26 & -0.45 & -0.52 & -0.57 & -0.48 & -0.45 & -0.37 & -0.33 & -0.16 \\
\hline Yazd & -0.1 & -0.05 & 0.02 & 0.09 & 0.02 & -0.06 & 0.1 & 0.13 & -0.04 & -0.12 & -0.08 & -0.11 \\
\hline Zabol & -0.73 & -0.75 & -0.74 & -0.77 & -0.54 & -0.36 & -0.19 & 0.05 & -0.32 & -0.59 & -0.34 & -0.66 \\
\hline Zahedan & -0.2 & -0.17 & -0.13 & 0 & -0.06 & -0.22 & -0.17 & -0.1 & -0.09 & -0.2 & -0.13 & -0.14 \\
\hline Zanjan & -0.56 & -0.52 & -0.53 & -0.54 & -0.73 & -0.68 & -0.77 & -0.78 & -0.75 & -0.78 & -0.77 & -0.61 \\
\hline
\end{tabular}

example, significant decreasing trend for winter occurs with 44.4 and $30 \%$ of the studied stations based on Pearson method and the Mann-Kendall method. On the other hand, the frequency of increasing significant trend for Pearson method is $8.3 \%$ and for Mann-Kendall test, it is $5.8 \%$ only (Table 5, Fig. 5). In this season, according to both methods, February and December have the greatest ratio of increasing and decreasing trend of PET. Considering the changes in decadal averages of PET in winter, the highest decrease in decadal averages of December belongs to Semnan with $-2.5^{\circ} \mathrm{C}$, while Zabol experienced the highest decrease with $-3.0{ }^{\circ} \mathrm{C}$ in January and $-3.0{ }^{\circ} \mathrm{C}$ in February (Table 6). Esfahan has the 

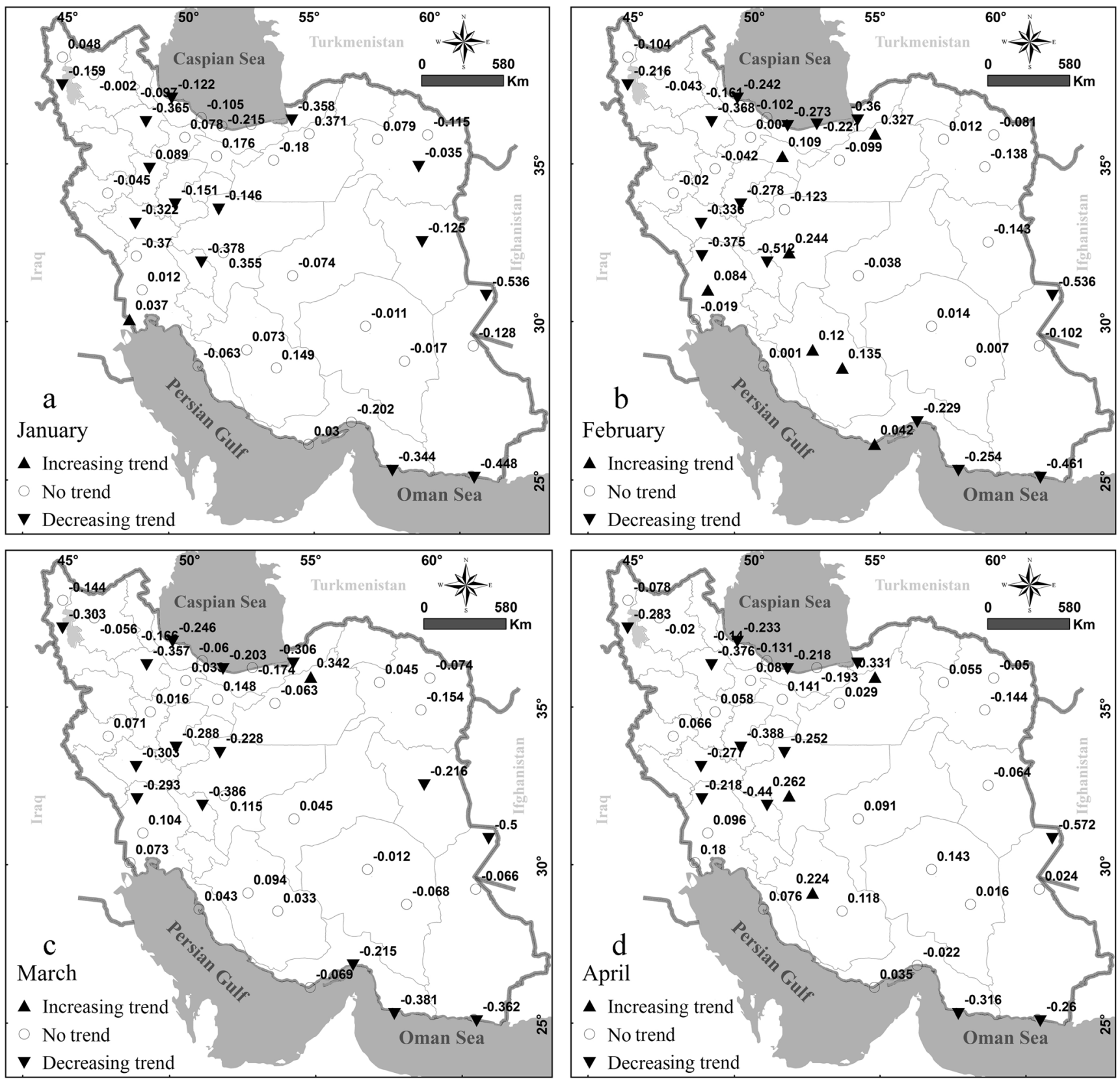

Fig. 5 Assessing meaningfulness of PET using Mann-Kendall test for the studied Iranian areas from January (a) to April (d). Data are based on long-term monthly changes of PET, indicating the areas with increasing, decreasing, and no trend. Assessing meaningfulness of PET using MannKendall test for the studied Iranian areas from May (e) to August (h). Data

highest increasing changes of PET in this season, as its decadal average showed an increase of $1.5^{\circ} \mathrm{C}$ for December, $1.6^{\circ} \mathrm{C}$ for January, and $1.1{ }^{\circ} \mathrm{C}$ for February (Table 6).

The distribution of spatial and temporal trend changes for different months shows that in January, the most significant trends are decreasing with the maximum distribution covering the west and northwest stations of the country. On the other hand, most of the stations in the inner regions of Iran do not have a significant trend (Fig. 5). In Table 6, PET decadal are based on long-term monthly changes of PET, indicating the areas with increasing, decreasing, and no trend. Assessing meaningfulness of PET using Mann-Kendall test for the studied Iranian areas from September (i) to December (I). Data are based on long-term monthly changes of PET, indicating the areas with increasing, decreasing, and no trend

changes for January reflect that $7.5,27.5$, and $40 \%$ of the stations experience increasing decadal changes of more than $2{ }^{\circ} \mathrm{C}$, between 1 and $2{ }^{\circ} \mathrm{C}$ and between 0 and $1{ }^{\circ} \mathrm{C}$, respectively. Moreover, $20 \%$ of them have decrease in decadal changes between 0 and $1{ }^{\circ} \mathrm{C}$, and $5 \%$ of them have decrease between -1 to $-2{ }^{\circ} \mathrm{C}$. In February, several areas of Iran show different PET trend changes. For example, stations adjacent to the shoreline of the Sea of Oman have decreasing trend but it is increasing in the stations located in the Persian Gulf coastal 

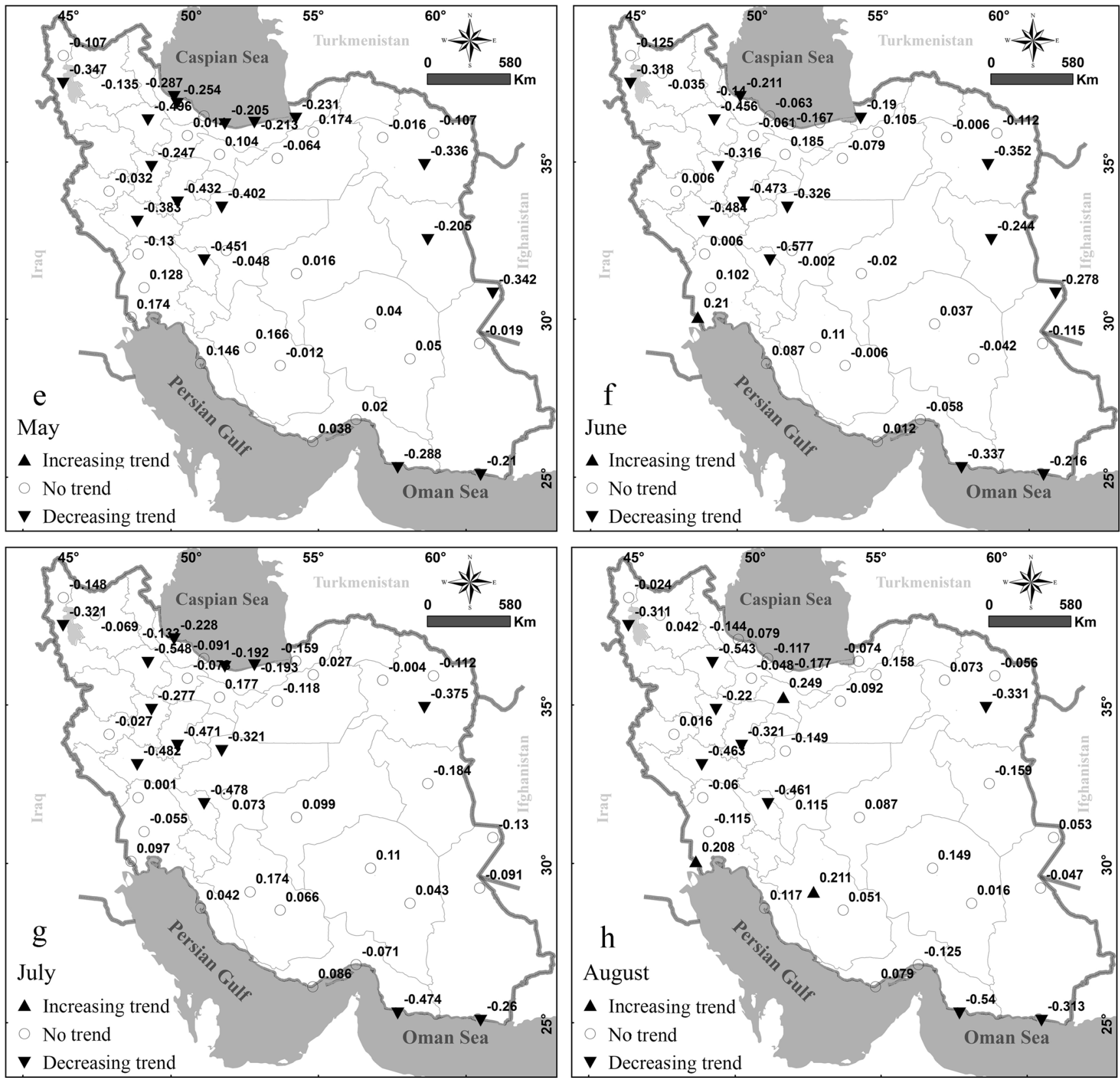

Fig. 5 continued.

strip. On the other hand, for stations located in the southern coasts of Caspian Sea, the decreasing trend is significant; however, in stations of most of the eastern half of the country, trends are accidental (Fig. 5). In this month, mean decadal changes with a frequency of $80 \%$ of the stations refer to the decreasing trend, and the decreasing class of 0 to $-1{ }^{\circ} \mathrm{C}$ with a frequency of $42.5 \%$ of the studied stations has the maximum density among the stations. In this month, only $20 \%$ of the stations experience an increase in PET decadal mean and their distribution fluctuates between an increase of 0.01 to $1.1{ }^{\circ} \mathrm{C}$ (Table 6). In March, decreasing trend is dominant and except for internal and central regions of Iran, a significant decreasing trend of PET can be observed (Fig. 5). In this month, $32.5 \%$ of the stations have increasing decadal changes between 0.03 to $1.1{ }^{\circ} \mathrm{C}$ and in the remaining $67.5 \%$ cases, decreasing change occurs between the minimum of -0.13 and the maximum of $-2.78^{\circ} \mathrm{C}$ (Table 6).

In spring, the output of Pearson method indicates that the frequencies of stations with significant decreasing and increasing trend are 49.2 and $5.8 \%$, respectively, while these values are 37.7 and $3.3 \%$ by applying Mann-Kendall method. Both methods signal April and May to have the highest frequency of stations with significant decreasing and increasing trends (Table 5, Fig. 5). In this season, Zabol, Zanjan, and 

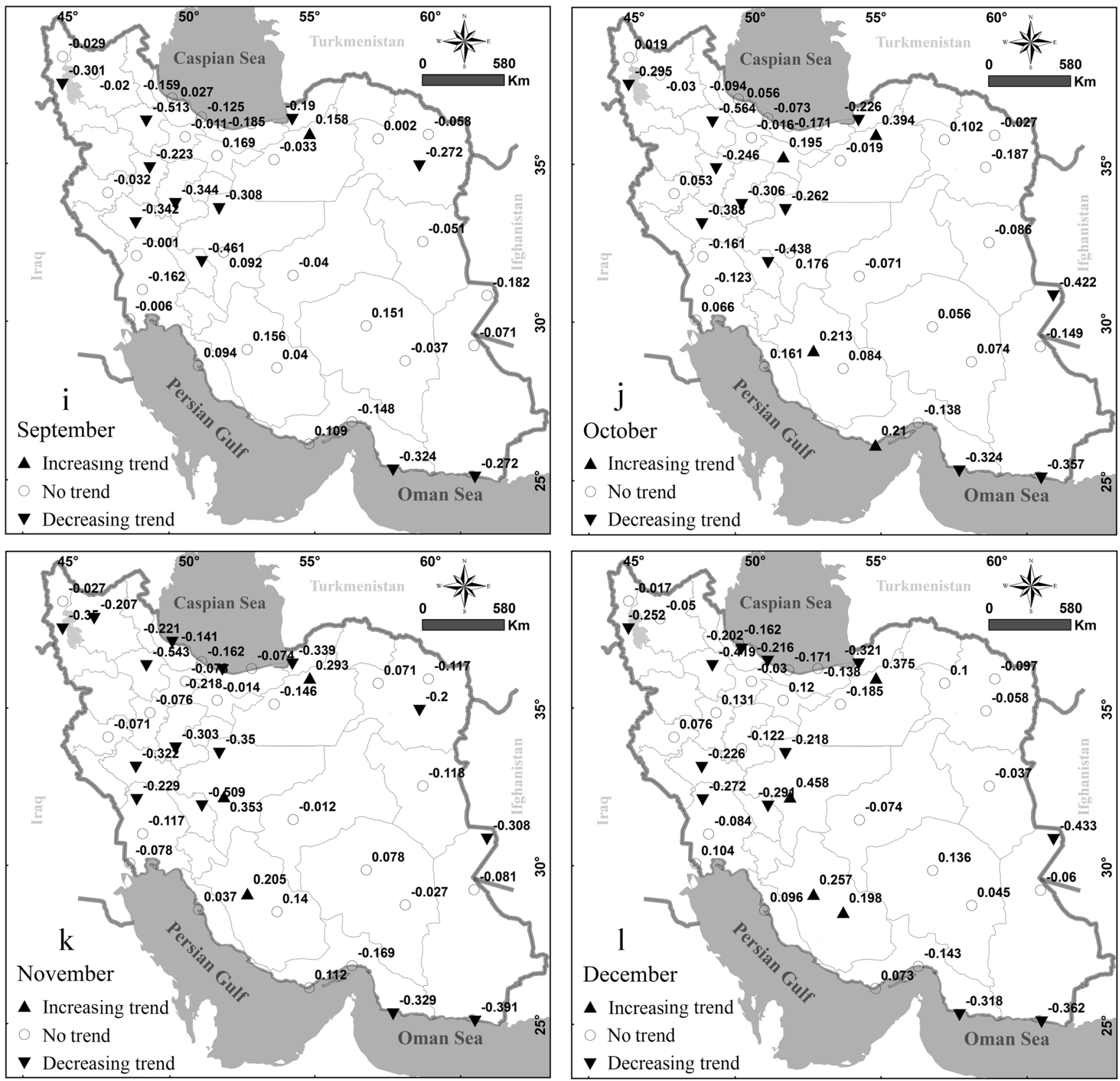

Fig. 5 continued.

Shahrekord show the highest reduction in decadal average of PET with $-2.8,-2.6$, and $-2.5^{\circ} \mathrm{C}$, respectively. However, the highest increase in decadal average of PET occurs in Esfahan in March with an increase of $1.1^{\circ} \mathrm{C}$ and in Ahvaz in April and March with values of 1.3 and $1.0^{\circ} \mathrm{C}$ (Table 6).

Based on the spatio-temporal distribution of monthly trend changes, which is shown in Fig. 5, there is no significant trend in Iran's eastern half in April except for the two stations in the coastal strip of the Oman sea and a station on the eastern border of the country. The maximum density of significant trend occurs in the western half of the country with the dominance of decreasing trend. Interestingly, this spatial distribution of monthly changes for May and June is similar to April (Fig. 5). It is necessary to mention that decadal mean of PET changes is decreasing for $62.5 \%$ of the stations in April; however, in May and June, 72.5 and $77.5 \%$ of the stations have decreasing mean of PET changes (Table 6).

In summer, no significant increasing trend of monthly PETs is observed in June and July; however, August indicates a frequency of $7.5 \%$ of significant increasing trend based on both statistical tests. The ratio of significant decreasing trend in this season is remarkable, as it occurs with 47.5 and $29.5 \%$ frequencies based on the two tests, respectively (Table 5, Fig. 5). For summer, 
Table 6 Changes in decadal averages of PET in each month for the studied Iranian stations

\begin{tabular}{|c|c|c|c|c|c|c|c|c|c|c|c|c|}
\hline Stations & Jan & Feb & Mar & Apr & May & Jun & Jul & Aug & Sep & Oct & Nov & Dec \\
\hline Abadan & -0.24 & -0.26 & 0.03 & 0.13 & 0.17 & 0.17 & 0.06 & 0.35 & -0.10 & 0.14 & -0.56 & -0.32 \\
\hline Ahvaz & 0.30 & 0.69 & 0.97 & 1.31 & 0.89 & 0.63 & -0.31 & -0.12 & -0.95 & -0.71 & -0.48 & 0.04 \\
\hline Anzali & -0.98 & -1.15 & -1.37 & -1.88 & -2.10 & -1.70 & -1.33 & -1.11 & -0.93 & -0.71 & -1.02 & -1.05 \\
\hline Arak & -1.64 & -1.61 & -1.18 & -1.68 & -2.40 & -2.34 & -2.05 & -1.64 & -2.09 & -1.63 & -2.00 & -1.28 \\
\hline Babolsar & -1.19 & -1.22 & -1.13 & -1.50 & -1.81 & -1.35 & -1.30 & -0.98 & -0.95 & -0.73 & -0.77 & -1.10 \\
\hline Bam & -0.61 & -0.41 & -0.34 & 0.12 & 0.22 & 0.06 & 0.23 & -0.03 & -0.20 & -0.48 & -0.35 & -0.39 \\
\hline Bandarabas & -1.34 & -1.40 & -1.16 & -0.63 & -0.26 & -0.55 & -0.52 & -0.61 & -0.81 & -0.89 & -1.25 & -1.30 \\
\hline Bandarlenge & -0.31 & -0.05 & -0.30 & -0.01 & 0.01 & -0.13 & 0.03 & -0.02 & 0.09 & 0.13 & 0.02 & -0.27 \\
\hline Birjand & -0.64 & -0.60 & -0.51 & -0.36 & -0.81 & -0.88 & -0.72 & -0.90 & -0.69 & -0.63 & -0.56 & -0.57 \\
\hline Bushehr & -0.55 & -0.32 & -0.13 & -0.02 & 0.09 & -0.15 & -0.24 & 0.01 & 0.01 & 0.31 & -0.19 & -0.22 \\
\hline Chabahar & -1.81 & -1.51 & -1.10 & -0.64 & -0.59 & -0.60 & -0.87 & -0.86 & -0.97 & -1.08 & -1.33 & -1.33 \\
\hline Dezful & -1.22 & -1.04 & -0.76 & -0.54 & -0.35 & 0.50 & 0.89 & 1.09 & 0.61 & -0.28 & -0.43 & -0.60 \\
\hline Esfahan & 1.63 & 1.10 & 1.10 & 0.58 & -0.67 & -1.17 & -1.41 & -1.16 & -0.59 & 0.19 & 0.88 & 1.45 \\
\hline Fasa & 0.69 & 0.52 & 0.16 & 0.44 & -0.21 & -0.06 & 0.18 & -0.07 & -0.04 & 0.10 & 0.39 & 0.63 \\
\hline Ghazvin & 0.02 & -0.33 & -0.18 & -0.29 & -0.75 & -0.61 & -0.70 & -0.72 & -0.57 & -0.42 & -0.76 & -0.69 \\
\hline Gorgan & -2.33 & -2.26 & -1.89 & -2.26 & -2.29 & -1.65 & -1.26 & -1.14 & -1.26 & -1.52 & -2.17 & -2.12 \\
\hline Hamedan & 0.57 & 0.27 & 0.10 & -0.11 & -1.30 & -1.77 & -2.33 & -2.12 & -1.60 & -1.20 & -0.75 & 0.26 \\
\hline Jask & -1.65 & -1.19 & -1.41 & -1.32 & -0.89 & -0.96 & -1.27 & -1.58 & -1.43 & -1.30 & -1.66 & -1.90 \\
\hline Kashan & -0.87 & -0.80 & -0.80 & -1.10 & -1.89 & -1.06 & -1.39 & -0.56 & -1.34 & -1.05 & -1.45 & -1.30 \\
\hline Kerman & 0.07 & 0.01 & 0.09 & 0.29 & 0.05 & 0.09 & 0.27 & 0.38 & 0.24 & 0.27 & 0.39 & 0.51 \\
\hline Kermanshah & -0.26 & -0.09 & 0.20 & 0.05 & -0.38 & -0.20 & -0.48 & -0.24 & -0.21 & 0.15 & -0.44 & -0.11 \\
\hline Khorramabad & -1.74 & -1.76 & -1.51 & -1.55 & -2.32 & -2.67 & -2.71 & -2.34 & -2.14 & -1.88 & -1.80 & -1.49 \\
\hline Khoy & -0.56 & -0.91 & -1.26 & -1.12 & -1.32 & -1.38 & -1.56 & -1.03 & -0.76 & -0.55 & -0.70 & -0.93 \\
\hline Mashhad & -0.38 & -0.21 & 0.03 & -0.16 & -0.46 & -0.43 & -0.49 & -0.43 & -0.33 & 0.06 & -0.43 & -0.45 \\
\hline Noshahr & -1.36 & -1.27 & -1.19 & -1.52 & -1.89 & -1.49 & -1.47 & -1.35 & -1.27 & -0.98 & -1.10 & -1.26 \\
\hline Orumieh & -1.43 & -1.57 & -1.98 & -1.52 & -2.17 & -2.15 & -2.33 & -2.17 & -2.07 & -1.71 & -2.12 & -1.78 \\
\hline Ramsar & -0.83 & -0.57 & -0.56 & -0.90 & -1.11 & -0.73 & -0.69 & -0.68 & -0.78 & -0.27 & -0.82 & -1.02 \\
\hline Rasht & -0.84 & -0.94 & -1.12 & -1.43 & -1.72 & -1.05 & -0.83 & -0.50 & -0.43 & -0.42 & -0.88 & -1.23 \\
\hline Sabzevar & 0.05 & -0.19 & 0.14 & 0.06 & -0.26 & -0.14 & -0.08 & -0.03 & -0.11 & 0.35 & 0.02 & 0.06 \\
\hline Semnan & -2.30 & -1.49 & -0.92 & -0.92 & -1.45 & -1.15 & -1.24 & -1.64 & -1.29 & -1.14 & -1.93 & -2.54 \\
\hline Shahrekord & -1.79 & -2.47 & -1.77 & -2.29 & -2.48 & -3.21 & -2.53 & -2.55 & -2.69 & -2.06 & -2.40 & -1.87 \\
\hline Shahrood & 1.05 & 0.68 & 0.71 & 0.56 & 0.11 & -0.05 & -0.23 & -0.10 & 0.43 & 1.14 & 0.59 & 0.65 \\
\hline Shiraz & 0.12 & 0.14 & 0.14 & 0.31 & 0.18 & 0.00 & 0.13 & 0.24 & 0.05 & 0.31 & 0.28 & 0.44 \\
\hline Tabriz & -0.31 & -0.22 & -0.26 & -0.63 & -1.05 & -0.68 & -0.74 & -0.31 & -0.12 & -0.05 & -0.89 & -0.61 \\
\hline Tehran & 0.62 & 0.49 & 0.56 & 0.18 & -0.09 & 0.47 & 0.43 & 0.59 & 0.71 & 0.70 & -0.10 & 0.18 \\
\hline TorbateHeidarieh & -0.21 & -0.34 & -0.37 & -0.61 & -1.21 & -1.53 & -1.40 & -1.24 & -1.30 & -0.76 & -0.67 & -0.46 \\
\hline Yazd & -0.39 & -0.17 & 0.14 & 0.06 & -0.04 & -0.20 & 0.19 & 0.16 & -0.13 & -0.17 & -0.20 & -0.23 \\
\hline Zabol & -2.95 & -3.02 & -2.78 & -2.25 & -1.36 & -0.87 & -0.32 & -0.13 & -0.87 & -1.49 & -1.36 & -2.41 \\
\hline Zahedan & -0.62 & -0.47 & -0.25 & -0.02 & -0.12 & -0.52 & -0.41 & -0.45 & -0.48 & -0.73 & -0.55 & -0.48 \\
\hline Zanjan & -1.80 & -1.66 & -1.34 & -1.64 & -2.57 & -2.57 & -2.92 & -2.77 & -2.76 & -2.31 & -2.64 & -2.01 \\
\hline
\end{tabular}

changes in decadal averages of PET fluctuate between -3.2 to $0.6{ }^{\circ} \mathrm{C}$ in Shahrekord and Ahvaz in June, while the greatest decrease is found in Zanjan in June and July with values of -2.9 and $-2.8{ }^{\circ} \mathrm{C}$. The greatest increase occurs in Dezfool in these 2 months with values of 0.9 and $1.1{ }^{\circ} \mathrm{C}$, respectively (Table 6).
Based on the spatio-temporal distribution of monthly changes of PET trend for different months of summer, the frequency of the trend is significant decreasing in most cases focusing on the mid-west and northwest of Iran. Except for Torbate Heidarieh station in the northeast of Iran and Jask and Chabahar stations in Oman's 


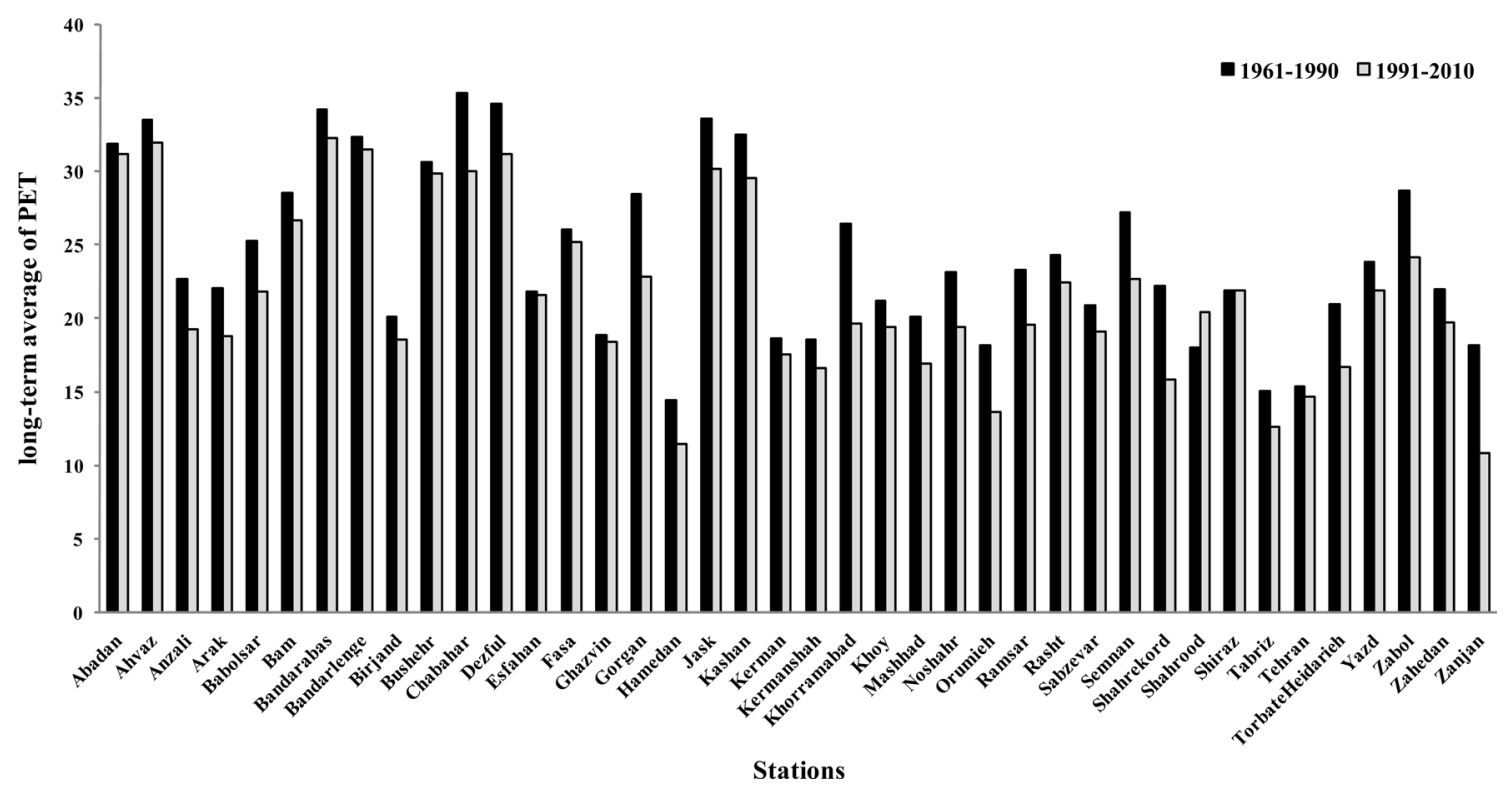

Fig. 6 Comparison of PET long-term average for the period of 1961 to 1990 with the period from 1991 to 2010

coastline, no significant trend can be observed in the eastern, internal, and central regions of Iran (Fig. 5).

Considering the changes of PET trends in the autumn's months, Pearson's method reflects that the changes of monthly average of PETs are significant in $52.7 \%$ of the stations, which can be separated into $45.3 \%$ of significant decreasing and $7.5 \%$ of significant increasing trend (Table 5). Using the Mann-Kendall method, the trend's changes are significant in $36 \%$ of the stations with $30.2 \%$ of decreasing and $5.8 \%$ of increasing trend (Fig. 5). In this season, November has the largest number of stations with a significant decreasing trend of PET, while October and September have that of with significant increasing trend. There is high fluctuation in the changes in decadal averages of PET. Zanjan experienced the highest decline for all three autumn months: -2.8 , -2.3 , and $-2.6{ }^{\circ} \mathrm{C}$ from September to November, respectively. However, the highest increases in decadal averages of PET are in Tehran with an increase of $0.7{ }^{\circ} \mathrm{C}$ for September, Shahrood with $1.1{ }^{\circ} \mathrm{C}$ in October, and Esfahan with $0.9{ }^{\circ} \mathrm{C}$ in November (Table 6).

Paying our attention to the spatio-temporal changes of PET monthly trend for the months of autumn, it is clearly evident that October, November, and December show almost the same pattern, with a slight difference to each other.Thus, in all 3 months, Shahrood and Shiraz stations have jointly significant increasing trend. Also, in all 3 months, no significant trend of PET monthly changes can be seen in central areas of Iran. Zabol is the only station with significant trend located on the eastern borders of Iran that has decreasing trend in all 3 months. Also, stations located in the coastal strip of the Gulf of Oman, south of the Caspian Sea, and west and northwest of Iran have significant decreasing trend (Fig. 5). According to the decadal average long-term changes, in October, $70 \%$ and in November and December, 82.5 and $77.5 \%$ of the stations have negative mean of decadal changes and this indicates the dominance of the decreasing changes of PET decadal changes on the increasing changes in the autumns' months (Table 6).

\section{Comparing PET long-term average based on the period of 1961 to 1990 with the period from 1991 to 2010}

In this phase of the research, in order to analyze the effects of global warming on the long-term mean changes of PET, the studied time series were divided into two periods: the basic period of 1961 to 1990 and the recent period of 1991 to 2010. As Fig. 6 shows, the interesting point is the reduction of longterm average for 1991 to 2010 compared to the basic period of 1961 to 1990 for all the studied stations except Shahrood station. At Shahrood station, PET long-term average shows an increase of $2.4^{\circ} \mathrm{C}$ compared to the basic period of 1961 to 1990. The maximum reduction in long-term average of the period of 1991 to 2010 compared with the basic period relates to Shahrekord station $\left(-6.4{ }^{\circ} \mathrm{C}\right)$, Khorramabad station $\left(-6.8^{\circ} \mathrm{C}\right)$, and Zanjan station $\left(-7.4^{\circ} \mathrm{C}\right)$. The important point is that the reduction of the long-term average of 1991 to 2010 compared with the basic period has no similar impact on all the stations. So, some stations, for example Ahvaz, Bandarabas, Chabahar, Jask, or Zabol, have a reduction in the effect of heat stress, or in other words, the average of the recent decade has gone far from the heat stress classes. However, in some other stations, such as Zanjan, Tabriz, 
Hamedan, or Orumieh, cold stress or the average of the recent decade approaches the cold stress classes.

\section{Comparison of monthly patterns of PET for areas representing the geographic and climatic diversity in Iran}

In the following cases, we consider the monthly patterns of PET of the ten stations only that represent geographical and climatic diversity of Iran (Table 4 and Fig. 7). At first, the stations of the Persian Gulf and the Oman Sea are analyzed. For these areas, Ahvaz is a representative station located in the western half of the Persian Gulf. Here, the long-term monthly PET averages are higher than those in nearby Bushehr and Jask until August, while in August and September, Bushehr and from October, Jask has the highest values. In Ahvaz, the monthly averages are focused in the very hot zone from late spring to late summer. This condition is limited to smaller period in Bushehr, i.e., for July and August, while it does not occur in Jask at all (Table 4). We can observe the highest degree of warm conditions (i.e., slightly warm to very hot classes) and the smallest ratio of the cold stress classes in Ahvaz according to the long-term monthly frequencies of the thermal comfort classes. As Fig. 7 shows, the frequencies of very hot days of June, July, and May in Ahvaz are 94.5, 88.9 , and $81.6 \%$, respectively. For Bushehr, the frequencies of very hot days with 75.3 and $64.4 \%$ belong to August and July, while for Jask, June has the maximum experience of very hot days with $48.8 \%$ of frequency of the studied period. As long-term monthly averages for these three stations show, thermal comfort is limited to late autumn up to early spring (Table 4). However, according to the monthly frequencies of classes, the highest degree of thermal comfort conditions for Ahvaz is 28.2 and $20.8 \%$ occurring in January and November, while in Bushehr, March and November with values of 38.8 and $29.6 \%$, and in Jask, February and January with values of 43.8 and $41.9 \%$ have the greatest ratio of days with thermal comfort (Fig. 7).

Assessments of two coastal stations of the Caspian Sea reveal that Rasht, the representative of southwest coast of the Caspian Sea, indicates higher monthly PET averages from March to July, while Babolsar, the representative of southeast of the Caspian Sea, from August to February (Table 4). The most important inhibiting factor of thermal comfort is the hot condition in summer and the cool condition in winter based on the monthly averages of PET (Table 4), while on the basis of the monthly frequencies, hot to very hot conditions in summer and cool to very cold conditions in winter inhibit thermal comfort (Fig. 7). The monthly frequency of daily data for Rasht shows that August, July, and June experiences the highest degree of hot condition, with values of $40.3,39.7$, and $29.9 \%$. These values for Babolsar are 51.2, 44.5, and
$35 \%$ (Fig. 7). Considering the thermal comfort conditions, long-term monthly averages are located in the thermal comfort zone in April and November in these cities (Table 4), while this occurs most frequently also in these 2 months according to the monthly frequencies of PET, i.e., 25.3 and $24.2 \%$ for Rasht and 28.1 and $28.9 \%$ for Babolsar (Fig. 7).

Turning our attention to the two central stations of Iran, long-term monthly averages of PET for most months are slightly higher in Yazd than in Shiraz (Table 4). In these two stations, the long-term averages of October and April are located in the thermal comfort zone, and the monthly frequency of daily data shows that thermal comfort conditions occur with frequencies of 42.6 and $38.2 \%$ in Shiraz and 36.3 and $35.9 \%$ in Yazd in October and April. In these two stations, the most inhibiting period for thermal comfort is winter and summer. For example, 62.5 and $51.4 \%$ of days of January are located in the cold to very cold class in Yazd and Shiraz, while this is 85.3 and $70.1 \%$ for the hot to very hot zone in July in these cities (Fig. 7).

Long-term monthly averages of PET for Tehran, the representative station of northern half of the country and capital of Iran, show that thermal comfort occurs in May in this city only with $19.9^{\circ} \mathrm{C}$ of PET (Table 4). Also, the monthly frequencies of PET values for May show that $35.4 \%$ of the days are located in the thermal comfort zone (Fig. 7). The most inhibiting period of bioclimatic condition of thermal comfort is winter, which can be related to the high occurrence of cold to very cold events: $87.5,94.3$, and $87.7 \%$ from December to February. On the other hand, July experienced the highest frequency of warm to very hot event with the occurrence of $63.8 \%$ (Fig. 7).

Mashhad is another selected station of Iran with its specific geographical and climatic situation. Here the highest monthly average of PET belongs to July $\left(33.5{ }^{\circ} \mathrm{C}\right)$ and the lowest to January $\left(4.1{ }^{\circ} \mathrm{C}\right)$ (Table 4). This feature is reflected in the monthly frequencies, i.e., $35.8 \%$ of the days include hot to very hot conditions in July and $71 \%$ include cold to very cold conditions in January (Fig. 7). Days with thermal comfort can be found in April and May only in terms of the long-term monthly averages with values of 18.8 and $23{ }^{\circ} \mathrm{C}$ (Table 4). Therefore, by evaluating the monthly frequencies of daily data of the study period, 27.6 and $25.3 \%$ of the days in May and April are located in the thermal comfort zone, which incorporates the highest occurrence rates during the year.

Finally, in Tabriz, which is located in the northwest part of the country, the most important inhibiting period of thermal comfort is winter due to the high occurrence ratio of cold to very cold conditions (Table 4, Fig. 7). The results indicate that the long-term monthly averages of PET are the smallest in January, February, and December with values of $-3.1,0$, and $0.2{ }^{\circ} \mathrm{C}$ (Table 4 ). The monthly 


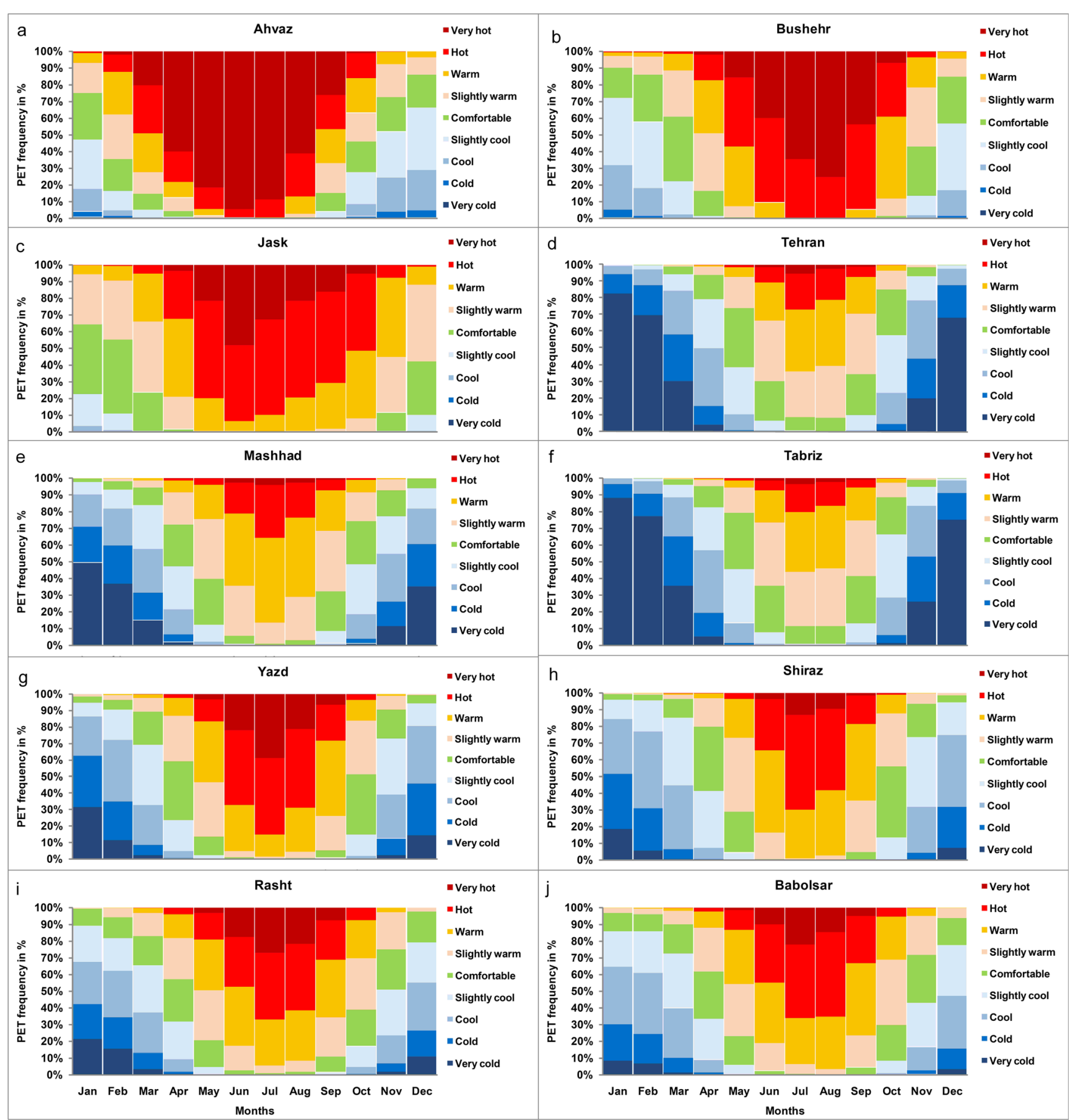

Fig. 7 Monthly frequencies of PET classes (\%) using daily data for ten different Iranian stations from Ahvaz (a) to Babolsar (j) representing the climatic and geographical diversity of Iran. The applied PET class

boundaries are based on the traditional thermal perception thresholds of PET in Table 1 (Matzarakis and Mayer 1996)

frequencies of data for the cold to very cold classes are 96.4, 90.6, and $90.8 \%$ for January, February, and December (Fig. 7). May is the sole month that is located in the thermal comfort zone with PET of $19^{\circ} \mathrm{C}$ considering the long-term monthly average (Table 4). On the other hand, based on the frequencies of daily data, $33.7 \%$ of the days are in the thermal comfort class in May, which is the highest value during the year (Table 4).

\section{Discussion}

This study aimed at investigating the long-term averages of PET and the changes of PET trend by applying the linear regression method and the Mann-Kendall test for 40 stations of Iran. The study utilized long-term daily data for the period of 1960 to 2010. Although some studies have been conducted in the past with the goal of determining bioclimatic conditions 
of some cities in Iran, most of them had several shortcomings. Firstly, they used monthly average data or their studied area was limited to one or two provinces only. Secondly, the goal of previous studies was to determine the bioclimatic conditions of the areas only; however, in this study, the trend of PET changes has also been evaluated. Also, as a part of this research, the PT index has been calculated and compared with PET.

The comparison of PET and PT showed that PET's bioclimatic thresholds are more sensitive in the monitoring of cold and warm bioclimatic conditions compared to PT, and this is more intense for the occurrence of cold bioclimatic conditions. However, the difference in the monitoring of thresholds led to the fact that a greater percentage of studying days were in the comfort range according to the outcome related to PT. It is worth noting that few studies have compared PET with PT for Iran. A study concerning some Iranian cities showed that the correlation of results for PET and PT method was not significant. However, the output of the two methods revealed a good overlap for heat stress events (Zamanei et al. 2010). Similarly, our findings confirmed that warm class had good overlap for PET and PT, and remarkable differences occurred in the cases of cold and thermal comfort classes.

Tahbaz et al. (2011) presented the results of a field study analysis that was carried out to reveal thermal conditions with different thermal indices (PT, temperature humidity index, heat index, humidex, tropical summer index, discomfort index, and wet bulb globe temperature) in outdoor public spaces of Amanieh region in Ahvaz city, Iran. By comparing the predicted thermal conditions with the local people and tourist behavior in the public spaces of Ahvaz, it was clear that two of these indices (PT and THI) were better suited to real conditions and thus they were selected as the most appropriate indices for climate conditions of Ahvaz. They showed that thermal conditions encompass very hot and extreme heat stress situation in a great part of the year in Ahvaz based on the thermal indices like PT. This result is in accordance with our finding for Ahvaz, which signaled that 68 and $64 \%$ of data were in the warm classes for the PET and PT, respectively (Fig. 2). Also, on basis of PET, Fig. 5 showed that great part of the year experienced hot and very hot thermal conditions. As previous mentioned, suitable conformity was found between PT and PET for warm classes, but the relationship for cold and thermal comfort classes of cold and comfort were weak.

In a research project presented by Tahbaz (2010), thermal indices of THI, PT, DI, TSI, WBGT, PET, and UTCI were studied and compared together in psychrometric chart (Tahbaz 2010). In this study, it became clear that these indices are not in accordance with each other. Therefore, using an index for a specific project in a city needs to be clarified by means of local observations to explore which index would be more suitable for predicting the thermal conditions of the study site.
Farajzadeh et al. (2015) compared simple thermal indices and indices derived from energy budget models for the northwest area of Iran. The results showed that the indices based on human energy balance had a significant correlation with each other (with $R^{2}$ above 0.9 ) and the lowest $R^{2}(0.7)$ was related to subjective temperature index (STI). The indices based on relatively simple formulas had low correlation with UTCI and PET. Our result showed that there has no conformity between PT and PET, especially for cold and comfort classes.

Analysis of the long-term average PET values indicates fluctuations from the very cold to very hot classes across months in our study. According to the spatiotemporal distribution of Iranian bioclimatic conditions, the most favorable days of the year with thermal comfort specific to the cold period of the year are related to midautumn to late winter in coastal cities of Persian Gulf and Oman Sea, including Bushehr, Bandar Abbas, Bandar Lengeh, and even Chabahar. In these stations, the most important inhibiting factor of thermal comfort event is warm to very hot conditions, which prevail from mid-spring until the end of summer. The results of this present research are to an extent in conformity with the results from previous studies conducted in recent years. As Roshan et al. (2015) showed that the cities located on the coast of the Persian Gulf and Oman Sea have the most favorable climate conditions for tourism in winter due to warm temperatures, clear skies, and rare occurrence of precipitation. The findings of Daneshvar et al. (2013) showed that spring months, especially April, had the most appropriate condition for thermal comfort in most regions of Iran; however, in southern cities, the ideal comfort conditions were related to winter. Also, Daneshvar et al. (2013) used long-term average monthly data to estimate PET index and examined thermal comfort conditions during different months of the year. Their results showed that thermal comfort conditions prevail during the winter months on the southern part of the country and along the shores of the Persian Gulf and Oman Sea.

In the present work, for coastal cities of Caspian Sea, the thermal comfort period is bimodal with shoulder peaks, i.e., it occurs during middle spring and fall. The most important inhibiting factor of bioclimatic conditions of these areas is related to the warm conditions during late spring to late summer. Roshan et al. (2015) showed that the cities on the coast of the Caspian Sea had the least favorable conditions based on the tourism climatic index (TCI) due to high rainfall volumes, low sunshine hours, and temperatures outside of comfort levels. Their results presented that spring and fall are the most suitable season there for tourism, similarly to this study. A study of the city of Anzali on the southern coast of the Caspian Sea, which analyzed effective temperature, found that climate best suited to the comfort index was experienced in 
spring, which is in agreement with the findings of this study again (Ramezani et al. 2013).

In the stations of west to northwest of Iran, for example in Tabriz, the most frequent thermal comfort condition appears in the form of two peaks, i.e., in late spring as well late summer and early fall. Farajzadeh and Matzarakis $(2009,2012)$ and Farajzadeh et al. (2015) investigated thermal climate and tourism climate conditions for the areas of northwest of Iran using PET. Based on calculations of PET in Ourmieh Lake coast, it is shown that the months June to September are located in the comfortable class representing the most suitable months for tourist activities. The minor difference between the results of the present study and those of the above-mentioned studies in northwest part of the country seems to be related to the fact that the period of time of those studies lasted until 2005, while the study period of the present study has been expanded to 2010. Therefore, it can be inferred that the global warming phenomenon in recent years has increased the temperature in the northwest, especially in the mid-summer, so that it has been above the thermal comfort and has shifted to early fall.

Our results showed that the most important inhibitory factor of thermal comfort in northwest and west areas is the cold to very cold climatic conditions, which prevail from late autumn to late winter. These results are in accordance with Farajzadeh and Matzarakis $(2009,2012)$.

This situation can be observed in this study for Mashhad station in northeast of Iran. Owing to the mausoleum of the Shiite's Eighth Late Leader (Imam Reza), Mashhad is Iran's most important religious tourism center. Besides, Firdausi's mausoleum (the greatest Persian epic poet who lived in tenth century) attracts millions of tourists annually. According to the records of Cultural Heritage and Tourism Organization of Khorasan Razavi, 25 to 30 million pilgrims and tourists visit Mashhad annually (Esmaili and Fallah Ghalhari 2014b). For Mashhad warm bioclimatic condition with a focus on summer, especially on July, is the most important inhibiting factor of thermal comfort. Esmaili and Fallah Ghalhari (2014b) showed for Mashhad that summer days are not ideal for tourism due to the heat stress. According to their findings, the daily course of PET shows a Gaussian curve, i.e., a peak in July due to heat stress. Moreover, based on both researches, majority of thermal comfort condition occurs in two periods during the year: middle spring and early fall.

In central stations of Iran, the most ideal bioclimatic condition was observed for two periods in this study: mid-spring and mid-autumn. Bakhtiari and Bakhtiari (2013) determined that the most suitable months for tourist activities for cities of Kerman and Bam, Kerman province, are displayed as a bimodal shoulder peak, which is in agreement with our outcomes for central stations of Iran.

A study for the city of Shiraz found changes in bioclimatic trends in response to climate change that indicated more favorable conditions for cold seasons of the year in future
(Shakoor et al. 2008). Our results for Shiraz demonstrated that long-term monthly averages of PET for November and December are in classes of cool and slightly cool with regard to present time series. Also, these months had significant positive trends of PET, with approaching or reaching thermal comfort class, similarly to Shakoor et al. (2008).

Comprehensively, April and October tend to be the most appropriate months of the year for thermal comfort at the whole area of Iran according to this study. It can be concluded that this result is consistent with that of other studies conducted in Iran (Esmaili et al. 2011, Rezvani and Mesgarian 2015). Also, the results of Esmaili and Fallah Ghalhari (2014a) proved that the highest potential of thermal comfort in Iran was related to spring, followed by fall.

Besides the several discussed studies conducted in Iran, findings of some studies in Middle East are similar to our case study. Caliskan et al. (2012) evaluated the climate and bioclimate of Bursa in Turkey, neighboring Iran, for tourism activities. They showed that between the cold period with its strong cold stress (November-April) and the period of heat stress (early June to late August), transition periods with thermally comfortable conditions prevail. Matzarakis and Karagülle (2007) demonstrated that cold stress is a month earlier in Istanbul compared to Bursa. However, all these conditions are almost similar to Tabriz, Khoy, and Orumieh in northwest of Iran.

Long-term monthly average of PET for Tehran, Zanjan, Tabriz, and Hamedan are similar to that of the other higher altitude/latitude places, such as Sonnblick in the Austrian Alps (Matzarakis et al. 2012), Zavizan in the Croatian Dinaric Alps and Kredarica in the Slovenian Julian Alps (Zaninovic et al. 2006), Gothenburg in Sweden (Thorsson et al. 2011), and the Qinghai-Tibet Plateau (Li and Chi 2014). The prevailing thermal condition in all of these places is long, very cold winters. However, Iranian sites experience more warm summers in comparison with the above-mentioned places because their altitude and latitude are lower and they are affected by Azores high pressure in warm seasons.

A study for Pakistan found that long-term monthly average of heat index (HI) signals extreme danger values $\left(\mathrm{HI}>54{ }^{\circ} \mathrm{C}\right)$ from May to August and October for Baluchistan province. However, there are different results in southeast of Iran, namely in province of Sistano Baluchistan, neighboring Baluchistan province of Pakistan (Gadiwala and Sadiq 2008). In Iran, extreme heat stress (PET $>41{ }^{\circ} \mathrm{C}$ ) appeared in June for Chabahar, in July for Zabol, and there was no experience about extreme heat stress for Zahedan (Table 4).

\section{Conclusion}

In this study, bioclimate conditions and their changes and distribution over the years were analyzed in Iranian cities in 
order to provide necessary information for decision makers on various levels, including health, tourism, local energy management, and regional planning. The main conclusion of this paper is that the thermal consequences on humans of climate change have been underestimated. Changes in the overall bioclimatic conditions for humans are expected to be considerably greater than changes in air temperature alone. Changes in non-temperature factors such as short- and long-wave radiation appear to reinforce the first-order effects of temperature change.

The results showed that from the three proposed thermal classes (comfort, cold, and warm), the highest ratio of daily frequencies of bioclimatic condition of the 40 selected stations belonged to the warm class. The overall average of this class for the studied stations involved $51.4 \%$ of the studied period, followed by cold bioclimatic zone with $35.7 \%$, and finally by climate comfort with overall average of $12.9 \%$. In other words, it can be concluded that the most important inhibiting factor is related to the warm bioclimatic events in the occurrence of thermal comfort condition in Iran. From all stations, Kerman has the highest frequency of thermal comfort event with $17.4 \%$ of the studied days, while the highest ratio of cold and warm bioclimatic events belong to Hamadan and Chababar with 62.1 and $86.7 \%$, respectively.

In most regions of the world, the projected climate change will produce bioclimatic conditions that are more stressful for individuals (a PET of more than $35{ }^{\circ} \mathrm{C}$ indicates strong heat stress for Europeans), and they will have an impact on their health and well-being. The number of regions with PET $>35{ }^{\circ} \mathrm{C}$ will increase compared to present bioclimatic conditions, and the possibility of heat waves will also be enhanced. In addition, the changed thermal conditions will lead to higher energy consumption (and higher emissions of greenhouse gases) as a result of the increased need for cooling (Matzarakis and Amelung 2008). However, analysis of PET trends showed different conditions for Iran. Besides the comprehensive analysis of bioclimatic conditions of Iran, other important findings of this study focused on the detection of PET change trend. The results of long-term trend analysis for the period of 1960-2010 clearly showed that $55 \%$ of the stations had significant increasing trend in terms of thermal comfort class based on the Pearson method, and it was $40 \%$ based on Mann-Kendall test. Comparing the frequency of trends of proposed cold and warm bioclimatic classes, we can conclude that the stations' ratio is considerably greater in the case of increase of frequency trend of cold bioclimatic events than the increasing frequency trend of the warm events. This fact was not inferred from daily time series of data only but the average monthly time series confirmed the decrease trend of warm PET class for most stations and months of the year.
Interestingly, the geographical distribution of significance level and randomness of the trends at different times of the year revealed that most stations with a significant trend concentrated in west and northwest half of the country. On the other hand, for stations located in the center and eastern half of the country, trends were random and did not have significant levels. As the results showed, many stations experienced decreasing trend of PET for all months, with its maximum belonged to May and November. However, the consequences are different for the different stations and for the months. For example, decrease of PET trend for warm period of the year can result in closeness or entrance of some stations to the thermal comfort class. However, this fact can be expressed with a different consequence for the cold period of the year, with leaving the comfort class and moving toward colder classes. This fact can be applicable for west and northwest of Iran. Therefore, decreasing trend of PET for stations in cold regions has more potential compared to the warm areas.

Considering changes of PET trend for recent decades and intensified process of global warming, it is expected that Iran's bioclimatic conditions change so that the focus of most days with comfort are transferred to early spring and late autumn. However, these changes can act differently from the perspective of different geographical areas of Iran. Consequently, in a subsequent study, it is recommended to simulate the bioclimatic conditions of the coming decades using climate models and then compare the results with those of the present study.

\section{References}

Abegg B, Konig U, Buerki R, Elsasser H (1998) Climate impact assessment in tourism. Appl Geogr Dev 51:81-93

Amiranashvili A, Matzarakis A, Kartvelishvili L (2008) Tourism climate index in Tbilisi. Transactions of the Georgian Institute of Hydrometeorology 115:27-30

Auliciems A, de Dear R (1998) Thermal adaptation and variable indoor climate control. In: Auliciems A (ed) Advances in bioclimatology, Vol 5 human bioclimatology. Springer-Verlag, Berlin Heidelberg, pp. $61-86$

Bakhtiari B, Bakhtiari A (2013) Determination of tourism climate index in Kerman province. Desert 18:113-126

Basarin B, Lukić T, Matzarakis A (2015) Quantification and assessment of heat and cold waves in Novi Sad, Northern Serbia. Int J Biometeorol. doi:10.1007/s00484-015-1012-z

Brager G, Paliaga G, de Dear R (2004) The effect of personal control and thermal variability on comfort and acceptability. ASHRAE, AtlantaFinal Report ASHRAE RP-1161

Çaliskan O, Çiçek I, Matzarakis A (2012) The climate and bioclimate of Bursa (Turkey) from the perspective of tourism. Theor Appl Climatol 107:417-425 
Cengiz T, Akbulak C, Caliskan V, Kelkit A (2008) Climate comfortable for tourism: a case study of Canakkale. BALWOIS 2008, Ohrid, pp. $1-9$

Dalman M, Salleh E, Sapian AR, Tahir OM, Dola K, Saadatian O (2011) Microclimate and thermal comfort of urban forms and canyons in traditional and modern residential fabrics in Bandar Abbas, Iran. Mod Appl Sci 5:43-56

Daneshvar MRM, Bagherzadeh A, Tavousi T (2013) Assessment of bioclimatic comfort conditions based on physiologically equivalent temperature (PET) using the RayMan model in Iran. Cent Eur J Geosci 5:53-60

Delavar M, Moradifar A, Nikouseresht R (2012) Classification of tourism region in north area of Iran by using of TCI index (case of study: Guilan province). Australian J basic Appl Sci 6:384-396

Esmaili R, Fallah Ghalhari G (2014a) Seasonal bioclimatic mapping of Iran for tourism. Eur J Exp Biol 4:342-351

Esmaili R, Fallah Ghalhari G (2014b) An assessment of bioclimatic conditions for tourists - a case study of Mashhad, Iran. Atmos Clim Sci 4:137-146

Esmaili R, Gandomkar A, Habibi Nokhandan M (2011) Assessment of comfortable climate in several main Iranian tourism cities using physiologic equivalence temperature index. Physical geography Research Quarterly 75:1-18

Fanger PO (1972) Thermal comfort. McGraw-Hill Book Co., New York

Farajzadeh H, Matzarakis A (2009) Quantification of climate for tourism in the northwest of Iran. Meteorol Appl 16:545-555

Farajzadeh H, Matzarakis A (2012) Evaluation of thermal comfort conditions in Ourmieh Lake, Iran. Theor Appl Climatol 107:451-459

Farajzadeh H, Saligheh M, Alijani B, Matzarakis A (2015) Comparison of selected thermal indices in the northwest of Iran. Natural Environment Change 1:61-80

Gadiwala MS, Sadiq N (2008) The apparent temperature analysis of Pakistan using bio-meteorological indices. Pak J Meteorol 4:15-26

Gagge AP, Fobelets AP, Berglund LG (1986) A standard predictive index of human response to the thermal environment. ASHRAE Trans 92: 709-731

Höppe PR (1993) Heat balance modelling. Experientia 49:741-746

Höppe PR (1999) The physiological equivalent temperature - a universal index for the biometeorological assessment of the thermal environment. Int J Biometeorol 43:71-75

Hydarei H, Alijanei B (1999) Iran climate classification using multivariate statistical techniques. Physical geography researches 37:57-74 in Persian

Jendritzky G, Staiger H, Bucher K, Graetz A, Laschewski G (2000) The perceived temperature: the method of the Deutscher Wetterdienst for the assessment of cold stress and heat load for the human body. Internet Workshop on Windchill. Environment Canada, Fredericton, pp. 1-23

Jendritzky G, de Dear R, Havenith G (2012) UTCI — why another thermal index? Int J Biometeorol 56:421-428

Kim J-H, Min Y-K, Kim B (2013) Is the PMV index an indicator of human thermal comfort sensation. Int J Smart Home 7:27-34

Kovács A, Unger J, Gál CV, Kántor N (2016) Adjustment of the thermal component of two tourism climatological assessment tools using thermal perception and preference surveys from Hungary. Theor Appl Climatol 125:113-130

Krüger E, Drach P, Emmanuel R, Corbella O (2013) Assessment of daytime outdoor comfort levels in and outside the urban area of Glasgow, UK. Int J Biometeorol 57:521-533

Landsberg HE (1972) The assessment of human bioclimate. A limited review of physical parameters. World Meteorological Organization, Geneva Technical Note No 123

Li R, Chi X (2014) Thermal comfort and tourism climate changes in the Qinghai-Tibet Plateau in the last 50 years. Theor Appl Climatol 117:613-624
Lin T-P, Matzarakis A (2008) Tourism climate and thermal comfort in Sun Moon Lake, Taiwan. Int J Biometeorol 52:281-290

Lin T-P, Andrade H, Hwang R-L, Oliveira S, Matzarakis A (2008) The comparison of thermal sensation and acceptable range for outdoor occupants between Mediterranean and subtropical climates. Proceed 18th Int Congress on Biometeorology, International Society of Biometeorology, Tokyo

Matzarakis A, Amelung B (2008) Physiological equivalent temperature as indicator for impacts of climate change on thermal comfort of humans. Seasonal forecasts, climatic change and human health. Adv Glob Change Res 30:161-172

Matzarakis A, Endler C (2010) Adaptation of thermal bioclimate under climate change conditions - the example of physiologically equivalent temperature in Freiburg, Germany. Int J Biometeorol 54:479483

Matzarakis A, Karagülle Z (2007) Bioclimate information for climate therapy in Istanbul. In: Matzarakis A, de Freitas CR, Scott D (eds) Developments in tourism climatology, International Society of Biometeorology. Commission on Climate, Tourism and Recreation, Freiburg, pp. 166-171

Matzarakis A, Mayer H (1996) Another kind of environmental stress: thermal stress. WHO Newsl 18:7-10

Matzarakis A, Mayer H (1997) Heat stress in Greece. Int J Biometeorol 41:34-39

Matzarakis A, Rutz F, Mayer H (2007) Modelling radiation fluxes in simple and complex environments - application of the RayMan model. Int J Biometeorol 51:323-334

Matzarakis A, Rutz F, Mayer H (2010) Modelling radiation fluxes in simple and complex environments: basics of the RayMan model. Int J Biometeorol 54:131-139

Matzarakis A, Hammerle M, Koch E, Rudel E (2012) The climate tourism potential of Alpine destinations using the example of Sonnblick, Rauris and Salzburg. Theor Appl Climatol 110:645-658

McGregor GR, Markou MT, Bartzokas A, Katsoulis BD (2002) An evaluation of the nature and timing of summer human thermal discomfort in Athens, Greece. Clim Res 20:83-94

Mieczkowski ZT (1985) The tourism climatic index: a method of evaluating world climates for tourism. Can Geogr 29:220-233

Mokhtari M, Anvari M (2015) A comparative study of tourism comforting climate in Iran (case study in the Markazi province and southern Kharasan province of Iran) with TCI model in GIS environment. J Nov Appl Sci 4:151-156

Nastos PT, Matzarakis A (2013) Human bioclimatic conditions, trends, and variability in the Athens University Campus, Greece. Adv in Meteorol 2013:976510

Ndetto EL, Matzarakis A (2015) Urban atmospheric environment and human biometeorological studies in Dar es Salaam, Tanzania. Air Qual Atmos Health 8:175-191

Olgyay V, Olgyay A (1954) Application of climatic data to house design. US Housing and Home Finance Agency, Washington DC

Parsons KC (2003) Human thermal environments. The effects of hot, moderate and cold environments on human health, comfort and performance. Taylor \& Francis, London

Ramazanipour M, Behzadmoghaddam E (2013) Analysis of tourism climate index of Chaloos City. Int $\mathrm{J}$ of Humanities and Management Sciences 1:290-292

Ramezani Gourab B, Foroughe P (2010) Climatic potential of sport tourism in Anzali-Rezvanshahr coastal belt, South-west of Caspian Sea, Iran. Caspian J Env Sci 8:73-78

Ramezani B, Yehkohan FM, Shafaghati M (2013) Assessing and feasibility of climatic comfort in Bandar-e Anzali by effective temperature model and evans. Int J agric Crop Sci 6:825-832

Rezvani M, Mesgarian H (2015) Comparison of the standard equivalent temperature (SET) in the houses of Yazd (case sample: the house of Lariha, Arabzadeh, Shokuhi, Golshan, Mahmudi, Lariha2, Olia. J Appl Environ Biol Sci 4:38-46 
Roshan G, Yousefi R, Fitchett JM (2015) Long-term trends in tourism climate index scores for 40 stations across Iran: the role of climate change and influence on tourism sustainability. Int J Biometeorol. doi: $10.1007 / \mathrm{s} 00484-015-1003-0$

Roshan Gh. R, Ghanghermeh A, Attia S (2017) Determining new threshold temperatures for cooling and heating degree day index of different climatic zones of Iran. Renew Energy 101:156-167

Rudel E, Matzarakis A, Koch E (2007) Summer tourism in Austria and climate change. In: Oxley L, Kulasiri D (eds) MODSIM 2007 International Congress on Modelling and Simulation. Modelling and Simulation Society of Australia and New Zealand, pp 1934-1939

Safaeipoor M, Shabankari M, Taghavi T (2013) The effective bioclimatic indices on evaluating human comfort (a case study: Shiraz City). Geography and Environmental Planning J 50:47-51

Shakoor A, Roshan GR, Khoshakhlagh F, Hejazizadeh Z (2008) Effect of climate change process on comfort climate of Shiraz station. Iran. J Environ Health Sci Eng 5:269-276

Staiger H, Bucher K, Jendritzky G (1997) Gefühlte Temperatur. Die physiologisch gerechte Bewertung von Wärmebelastung und Kältestress beim Aufenthalt im Freien in der Maßzahl grad Celsius. Ann Meteorol 33:100-107 Annalen der Meteorologie 33: 100-107

Staiger H, Laschewski G, Grätz A (2012) The perceived temperature-a versatile index for the assessment of the human thermal environment. Part a: scientific basics. Int J Biometeorol 56:165-176

Steadman RG (1979) The assessment of sultriness. Part I: a temperaturehumidity index based on human physiology and clothing science. J Appl Meteorol 18:861-873

Taffé P (1997) A qualitative response model of thermal comfort. Build Environ 32:115-121
Tahbaz M (2010) Toward a new chart for outdoor thermal analysis. Proceeding of the Conference: Adapting to Change: New Thinking on Comfort, London

Tahbaz M, Djanlilian S, Moosavi F (2011) Outdoor public spaces with better microclimate condition a case study in Amanieh Ahvaz. 5thSASTech 2011. Khavaran Higher-education Institute, Mashhad

Terjung WH (1968) World patterns of the distribution of the monthly comfort index. Int J Biometeorol 12:119-151

Thorsson S, Lindberg F, Björklund J, Holmer B, Rayner D (2011) Potential changes in outdoor thermal comfort conditions in Gothenburg, Sweden due to climate change: the influence of urban geometry. Int J Climatol 31:324-335

Yahia MW, Johansson E (2013) Evaluating the behaviour of different thermal indices by investigating various outdoor urban environments in the hot dry city of Damascus, Syria. Int J Biometeorol 57:615-630

Yan YY (2005) Human thermal climates in China. Phys Geogr 26:163-176

Zamanei R, Sedaghat E, Elahei E (2010) Comparison of perceived temperatures and physiologically equivalent temperature for Iranian selected stations. J land use Planning 3:25-39 in Persian

Zaninovic K (2001) Biometeorological potential of Croatian Adriatic coast. Meteorological and hydrological service of Croatia. In: Matzarakis A, de Freitas CR (eds) Proceed first Int workshop on climate, tourism and recreation. International Society of Biometeorology, Commission on Climate, Tourism and Recreation, Halkidiki, pp. 257-265

Zaninovic K, Matzarakis A, Cegnar T (2006) Thermal comfort trends and variability in the Croatian and Slovenian mountains. Meteorol Z 15: 243-251 